\title{
Multi-scale debris flow vulnerability assessment and direct loss estimation of buildings in the Eastern Italian Alps
}

\author{
R. L. Ciurean ${ }^{1} \cdot$ H. Hussin ${ }^{2}$ C. J. van Westen ${ }^{2}$. \\ M. Jaboyedoff ${ }^{3} \cdot$ P. Nicolet $^{3} \cdot$ L. Chen ${ }^{2,4} \cdot$ S. Frigerio $^{5}$ • \\ T. Glade ${ }^{1}$
}

Received: 15 February 2016/ Accepted: 27 September 2016/Published online: 25 October 2016

(C) The Author(s) 2016. This article is published with open access at Springerlink.com

\begin{abstract}
Vulnerability assessment, as a component of the consequence analysis, represents a fundamental stage in the risk assessment process because it relates the hazard intensity to the characteristics of the built environment that make it susceptible to damage and loss. The objective of this work is to develop a quantitative methodology for vulnerability and loss assessment of buildings exposed to debris flows and apply it to a study area in NE Italy at local and regional scale. Using existing conceptual models of vulnerability and loss, this paper seeks to identify solutions for maximizing the information gained from limited observational damage data and a heterogeneous building data set. Two vulnerability models are proposed: Model 1 is based on the generation of empirical vulnerability curves using observed intensities; Model 2 takes into account multiple resistance characteristics of buildings and uses modeled debris flow intensities. The process intensity descriptor in both cases is debris flow height. The vulnerability values obtained with the local (Model 1) and regional (Model 2) models are further multiplied with the building value to calculate the minimum and maximum loss for each building in the study area. Loss is also expressed as cumulative probability calculated with Model 1 using a Monte Carlo sampling technique. The methodology is applied in the Fella River valley (northeastern Italian Alps), a region prone to multiple mountain hazards. Uncertainties are expressed as minimum and maximum values of vulnerability, market values and loss. The
\end{abstract}

R. L. Ciurean

roxana.liliana.ciurean@univie.ac.at

1 Department of Geography and Regional Research, University of Vienna, Vienna, Austria

2 Faculty of Geo-Information Science and Earth Observation (ITC), University of Twente, Enschede, The Netherlands

3 Institute of Earth Sciences, Faculty of Geosciences and Environment, University of Lausanne, Lausanne, Switzerland

4 Institute of Geophysics and Geomatics, China University of Geosciences, Wuhan, China

5 Research Institute for Geo-Hydrological Protection, CNR-IRPI, National Research Council of Italy, Padua, Italy 
results are compared with relevant published vulnerability curves and historical damage reports.

Keywords Building vulnerability $\cdot$ Loss $\cdot$ Uncertainty $\cdot$ Debris flow $\cdot$ Italy

\section{Introduction}

Extreme rainfall events frequently trigger slope instability phenomena of various types, as well as floods and flash floods in mountain regions worldwide. The reduction in possible future human and material losses is dependent on the design and implementation of effective mitigation strategies which require the assessment of risks before and after construction. These in turn rely not only on the analysis of the magnitude, frequency and intensity of the harmful events, but also on the comprehensive evaluation of exposed elements and their vulnerability (Hufschmidt et al. 2010; Mazzorana et al. 2012; Papathoma-Köhle et al. 2015). Risk in the context of disaster management is defined as "a combination of the consequences of an event and the associated likelihood/probability of its occurrence" (EC, p. 10, ISO 31010). For property, annual risk can be calculated as the product of the annual probability of the hazardous event, the probability of spatial impact by the hazard, the temporal spatial probability of the property, its vulnerability and value (AGS 2007; Fell et al. 2005).

Vulnerability is a key component in the quantitative risk assessment of natural hazards. Due to its complex nature and multitude of perspectives, many different concepts and methods to systematize vulnerability exist in the literature (Birkmann 2006; Cutter et al. 2003; Fuchs 2009). In general, the definitions within engineering or natural sciences describe physical vulnerability as the predisposition or inherent characteristics of an element at risk to be affected or susceptible to damage as a result of an impacting hazard with a given intensity (Glade 2003). In this work, vulnerability is defined as "the degree of loss to a given element, or set of elements, within the area affected by a hazard, expressed on a scale of 0 (no loss) to 1 (total loss)" (UNDRO 1984).

Landslide vulnerability assessment can be difficult due to the inherent complexity of the hazardous processes (Cardinali et al. 2002), as well as the spatial and temporal characteristics of the elements exposed (Glade and Crozier 2005b; van Westen et al. 2006). Some of the factors responsible for this are: complex characteristics of different landslide types and processes; limited information on preparatory, triggering and controlling conditions (Glade and Crozier 2005a); the lack of accurate or limited observational data for process intensity estimation (Papathoma-Köhle et al. 2011); absence or incomplete damage information, especially in terms of building damage data or lives lost related to the failure mechanism as a result of specific process impact (Fuchs et al. 2007); spatial and temporal variability of the exposed elements at risk. Due (but not limited) to these factors, uncertainty associated with the input data, models and output results is difficult to evaluate and was thus rarely considered in vulnerability assessments.

Within disaster risk modeling, different methodological approaches for landslide vulnerability assessment have been proposed, and these can be classified as qualitative, semiquantitative and quantitative (Fuchs et al. 2011). Uncertainty analysis is associated predominantly with the last category. Uncertainty can be defined as "any deviation from the unachievable ideal of completely deterministic knowledge of a relevant system" 
(Walker et al. 2003). Uncertainty in probabilistic risk assessments is generally classified based on three factors (Walker et al. 2003): (1) the location of uncertainty within the modeled system (e.g., inputs, parameters, outputs); (2) the level of uncertainty, which can vary between total ignorance and deterministic knowledge; and (3) the nature of uncertainty, due to the natural variability of the phenomena being described-(aleatory uncertainty) or due to imperfection of our knowledge (epistemic uncertainty) (Fell et al. 2005; Pate-Cornell 1996; Rougier and Beven 2013).

A standardized method to quantify physical vulnerability is the use of a vulnerability curve, also referred to as a vulnerability function, which mathematically expresses the relationship between the hazard intensity and the expected degree of loss (PapathomaKöhle et al. 2012). Also used are the fragility curves, which provide the conditional probability for a given element to be in or exceed a certain damage state for a given hazard intensity. Both vulnerability and fragility curves are derived from statistical analysis of loss/damage values which can be collected, modeled or assumed over a range of hazard intensities.

Physical vulnerability and associated uncertainty can be modeled empirically, using damage observations at building level as the main source of information. Although modeling based on observations is the most realistic, generation of vulnerability curves is often challenging because of data scarcity, inaccuracies, subjectivity and generalizations associated with building classification, damage state levels and intensity descriptors (Sterlacchini et al. 2014). Further advantages and limitations of this modeling approach are discussed in Papathoma-Köhle et al. (2015). Despite difficulties in collection and reliability of post-disaster information, as well as the uncertainty in selection of the approximation functions, they are most frequently used. Fuchs et al. (2007), Fuchs (2008), Akbas et al. (2009) and Papathoma-Köhle et al. (2012) developed vulnerability curves for torrent processes and debris flows based on real event damage information from the Austrian and Italian Alps. These studies used historical information as input data for both damage degree and process intensity. This is in contrast to Quan Luna et al. (2011), who combined numerically modeled debris flow intensities with building damage to calculate three empirical curves as a function of debris flow depth, impact pressure and kinematic viscosity. These outputs were applied in a quantitative debris flow risk assessment that expressed uncertainty using minimum, maximum and average values of direct economic losses to buildings (Quan Luna et al. 2014). Eidsvig et al. (2014) used confidence intervals and damage distribution probabilities for different intensity levels to indicate the uncertainty in the obtained empirical and fragility curves. The uncertainty in the hazard intensity was not taken into account. Similarly, Totschnig et al. (2011) and Totschnig and Fuchs (2013) investigated the uncertainties associated with the selection of a best-fit linear regression function and expressed it using uncertainty bands.

Analytical methods are less frequently used to model physical vulnerability than empirical ones because of their complexity and detailed input data requirements (Corominas et al. 2014). Nonetheless, the results take directly into account the uncertainty in parameters and models, providing an in-depth characterization of the structural behavior of buildings under different loads. Mavrouli and Corominas (2010) and Mavrouli et al. (2014) assessed vulnerability of reinforced concrete (RC) frame structures to rockfall impact, slow-moving landslides and rapid flow-type slides using finite element models and incorporating the uncertainty of the impact location and frame properties in the model. Negulescu and Foerster (2010) also proposed a methodology for deriving analytical fragility curves for RC frame structures subjected to differential settlements using a nonlinear static time-history analyses. 
Finally, physical vulnerability can be estimated based on engineering judgment, where the relationship between the degree of loss and intensity resorts on expert opinion. Although this approach is subjected to high uncertainties due to its dependence on individual experience, different studies have demonstrated their usefulness in areas where information is sparse and the respondents are qualified in the investigated problem. Winter et al. (2014) used such a method to derive fragility functions that provide the conditional probability for a road to be in or exceed a certain damage state for a given debris flow volume. Godfrey et al. (2015) developed an expert-based vulnerability index for buildings impacted by hydro-meteorological hazards; this was used together with transferred vulnerability curves to generate a specific curve for the investigated area. The level of consistency in subjective judgments was quantified using an inconsistency ratio (IR). Similarly, Guillard-Gonçalves et al. (2015) measured the variability around an expertbased mean vulnerability value using standard deviation in a local-scale landslide risk study.

Other important examples of uncertainty analysis models used in landslide vulnerability analysis are given by Uzielli et al. (2008) and Kaynia et al. (2008), who applied a firstorder second-moment (FOSM) approach to provide estimates of uncertainty in vulnerability by defining a central value (e.g., mean) and a measure of dispersion (e.g., variance) of the model input variables (i.e., susceptibility of structures and intensity).

Consequences are the effects resulting from the occurrence of a hazard, such as economic loss, disadvantage or gain, damage, injury or loss of life (Crozier and Glade 2005). In the case of buildings, the direct monetary loss associated with landslide activity is obtained by multiplying the vulnerability and monetary value of each building. There are two main approaches for the calculation of economic loss: using (1) building market value (Blahut et al. 2014; Remondo et al. 2008; Silva and Pereira 2014) or (2) based on building reconstruction costs (Fuchs et al. 2007; Papathoma-Kohle et al. 2012; Quan Luna et al. 2014).

The common approach for obtaining a vulnerability curve is the application of linear regression analysis (Totschnig and Fuchs 2013). A distribution function (e.g., Weibull, exponential, Gamma) is proposed, and best-fit parameters of an average function are calculated using different statistical tests, such as coefficient of determination. However, this approach can be misleading due to overfitting issues, especially when the number of observations is reduced, and it is difficult to apply when the amount of scatter in the data set is high (Harrell 2001). We propose to adapt this methodology so that a distribution function zone is calculated, which is bounded by a minimum and a maximum vulnerability curve. If the degree of scatter is high, a second distribution function can be used to describe the data set within the minimum and maximum vulnerability curves previously defined. This approach is applied at local scale in the study area in order to maximize the information gain from limited historical damage observations.

Similarly to the challenge of defining landslide hazard based on a single intensity descriptor (Keiler 2011), assessing the vulnerability of structures to landslide impact using one physical characteristic may contribute to increased levels of uncertainty in the vulnerability estimates. For example, it is expected that buildings pertaining to the same occupancy and structural type, such as residential brick-masonry buildings, are different in terms of height, geometry or age; this may result in different responses to debris flow impact. To better characterize the vulnerability of various building types in the study area, a parametric (resistance) model is applied at regional scale. Such a model takes into account different physical characteristics of the building to define quantitatively a relationship between its resistance and the debris flow intensity (Du et al. 2014; Li et al. 2010). 
To our knowledge, the conceptual model applied herein has not been tested in a real case study. The two vulnerability models (empirical-Model 1, parametric-Model 2) are subsequently compared and used in direct loss estimation of the August 2003 extreme event in the Fella River valley, located in the northeastern Italian Alps.

The process of data collection regarding the value and structural characteristics of individual buildings at regional scale is very time-consuming and leads to difficulties in achieving accurate loss estimates, not only due to uncertainty in the physical effect of debris flow impact, but also due to disparities between areas with different land-use pattern (Blahut et al. 2014; Fuchs et al. 2012). To account for such differences, and due to the lack of information on reconstruction costs, a minimum and a maximum market value is used to assess direct economic loss. The obtained loss estimates are then compared with reported damages and results in other studies.

There are few regional vulnerability and loss studies that represent their pattern spatially, and most of them use discrete values (Silva and Pereira 2014). In this paper, discrete values of vulnerability and loss are represented spatially at individual building level, while continuous values are used to illustrate graphically the loss for a set of buildings, at local and regional scale. Maps representing the vulnerability and loss of exposed buildings can be useful in emergency planning, whereas vulnerability curves and probability loss distributions may help decision makers formulate strategies for rehabilitation/reconstruction investments in a given municipality or region.

The objective of this work is to develop a quantitative methodology for vulnerability and loss assessment of buildings exposed to debris flows and apply it to a study area in NE Italy at local and regional scale. The specific contribution of this work is the adaptation of existing vulnerability models to site-specific data sets and their application at various spatial scales. Moreover, the proposed methodology analyzes and partially quantifies uncertainties associated with vulnerability and loss assessment.

\section{Study area}

The Fella River valley is part of the upper section of the Tagliamento River Basin, which drains the Friuli-Venezia Giulia Region (FVG, northeastern Italian Alps). The area is characterized by rugged topography due to the faulted and densely fractured Permian and Triassic bedrock (mainly dolomite, limestone and calcareous marls), as well as high seismic activity. The landscape is predominantly mountainous, with high relief amplitude (between approximately 420-2750 m a.s.l) and slopes covered with deciduous or coniferous forests. Debris accumulation fans and alluvial deposits dominate the lower part of the slopes and river channels, respectively. The region is characterized by frequent heavy precipitation. Due to the lithological, structural and morphologic predisposition of the terrain, heavy convective precipitations result often in flash floods, floods, debris flows as well as shallow and deep-seated slides (Borga et al. 2007).

The administrative units overlapping the study area are Malborghetto-Valbruna, Pontebba, Tarvisio and Dogna municipalities. This territory presents high national interest due to its strategic position, at the border with Slovenia and Austria, which resulted in years of urbanization and development of a dense infrastructure network (Malek et al. 2014). Nevertheless, it has a low population density, ranging between 2.26 inhabitants $/ \mathrm{km}^{2}$ in Dogna and 22 inhabitants $/ \mathrm{km}^{2}$ in Tarvisio (ISTAT, 2014). Seasonal tourism, which is the main source of income in the area, accounts for a high variation in population density 
throughout the year. Considering the available damage information and the objective of this paper, two scales of analysis are used: (1) regional, in which residential structures within the entire study area are considered, and (2) local, encompassing residential buildings within the Malborghetto-Valbruna commune (Fig. 1).

An intense rainfall in the afternoon of August 29, 2003, affected the easternmost sector of the Italian Alps over an area of approximately $200 \mathrm{~km}^{2}$, overlapping mainly the Tarvisio, Malborghetto-Valbruna, Pontebba and Dogna communes. The convective system resulted as a combination of two extreme events, since very large accumulations of rainfall over 3-6 h occurred at the end of a climatic anomaly of prolonged drought and warm conditions in Europe and over the Mediterranean (Borga et al. 2007). The rainfall, lasting about $12 \mathrm{~h}$ in total, with a maximum intensity of $101.3 \mathrm{~mm} / \mathrm{h}$ and a cumulative precipitation of $389 \mathrm{~mm}$, resulted in debris flow processes with volumes ranging between few hundreds to ten thousand cubic meters and extreme values roughly attaining $100,000 \mathrm{~m}^{3}$ (Friuli-Venezia Giulia Civil Protection, 2012). The Fella River and its tributaries experienced floods and flash floods, respectively, with channel sections resulting in temporary sediment overload leading to destruction or burial of bridges, hundreds of meters of road

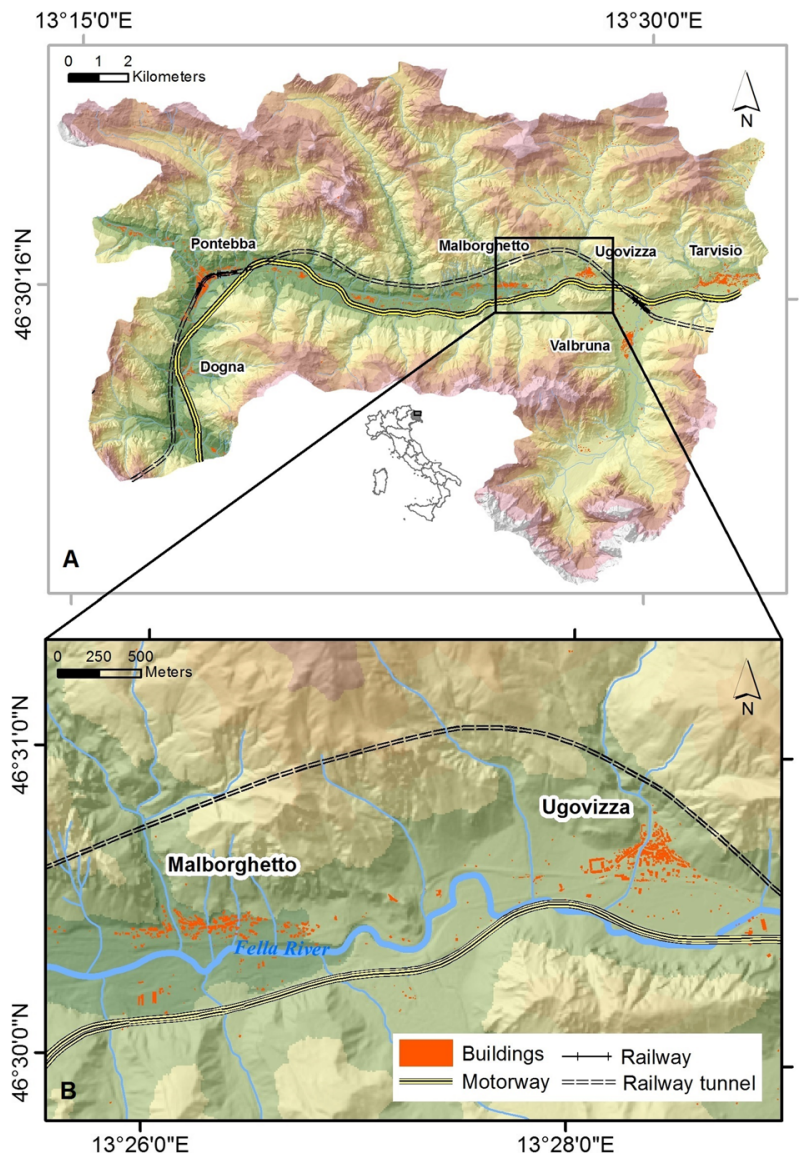

Fig. 1 Location of the study areas: A regional scale (Fella River valley); B local scale (Malborghetto and Ugovizza settlements, Malborghetto-Valbruna commune) 
segments and narrow valley floors. Debris flow material, often $2 \mathrm{~m}$ thick, and muddy water flash-flood deposits affected settled areas or scattered houses along the lower part of the slopes, causing the loss of two lives and at least 1 billion Euros of damage costs (Fig. 2). Reports of the Civil Protection state that direct losses to companies and private buildings (excluding infrastructure and mitigation works) caused by floods and debris flows in Malborghetto-Valbruna, Pontebba, Tarvisio and Dogna communes reached a total of 59.5 million Euros, out of which $61 \%$ were registered in Malborghetto-Valbruna alone.

\section{Data and methodological framework}

The methodological framework proposed in this study can be divided in two parts, each accounting for a conceptual model and scale of analysis. Each part consists of two methodological steps: (1) vulnerability assessment and (2) loss estimation. Figures 3 and 4 describe graphically the two methodological workflows. At local scale (Fig. 3), vulnerability is calculated empirically as the ratio between the damage costs and building monetary value (Model 1). Debris flow intensity described using debris height (measured in centimeters) is estimated at each impacted building from photo-documentation (Papathoma-Köhle et al. 2012). To generate minimum and maximum vulnerability curves, distribution functions are selected and their parameters calculated through regression analysis. In a second step, building market value is used together with the vulnerability value and its associated intensity to calculate the cumulative probability of loss using Monte Carlo sampling.

At regional scale (Fig. 4), vulnerability is calculated on the basis of a conceptual model proposed by Li et al. (2010), which takes into account multiple physical resistance characteristics of buildings (Model 2). The process intensity is estimated as a function of
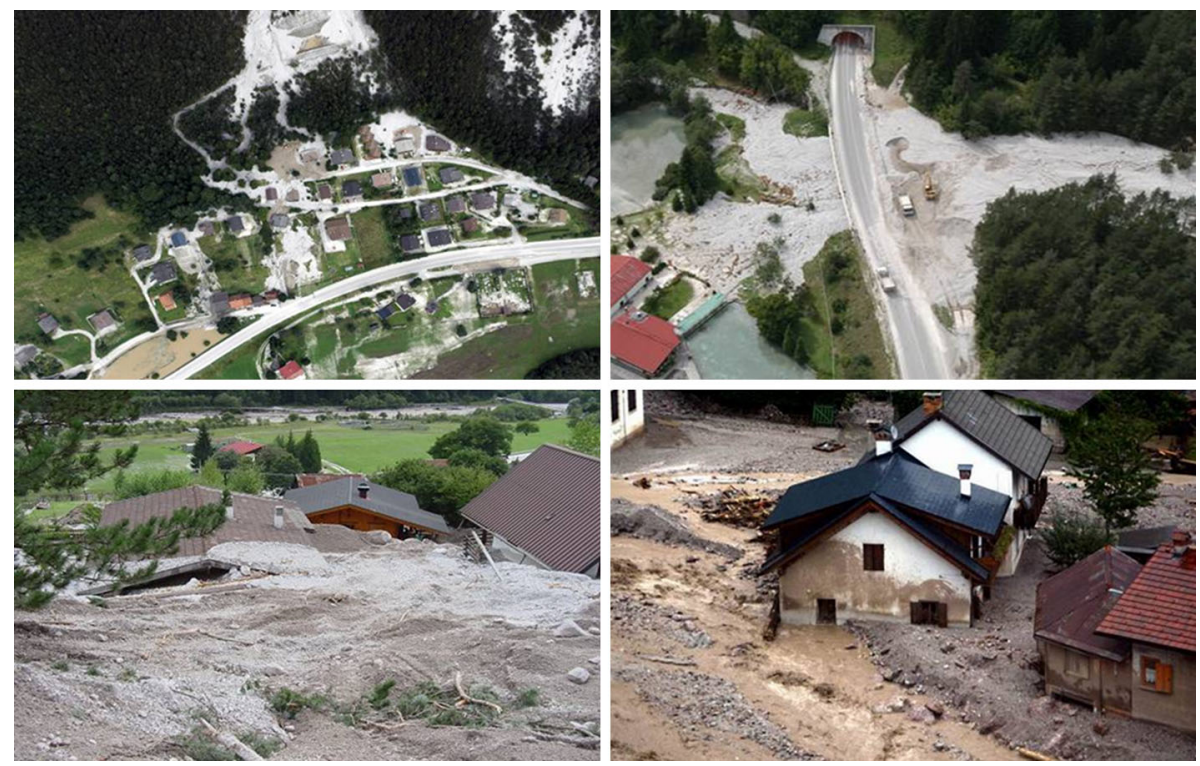

Fig. 2 Damage produced by debris flows and flash floods to infrastructure and buildings in the aftermath of the August 2003 event (source: Civil Protection, FVG Region, 2012) 
Source: regional building database

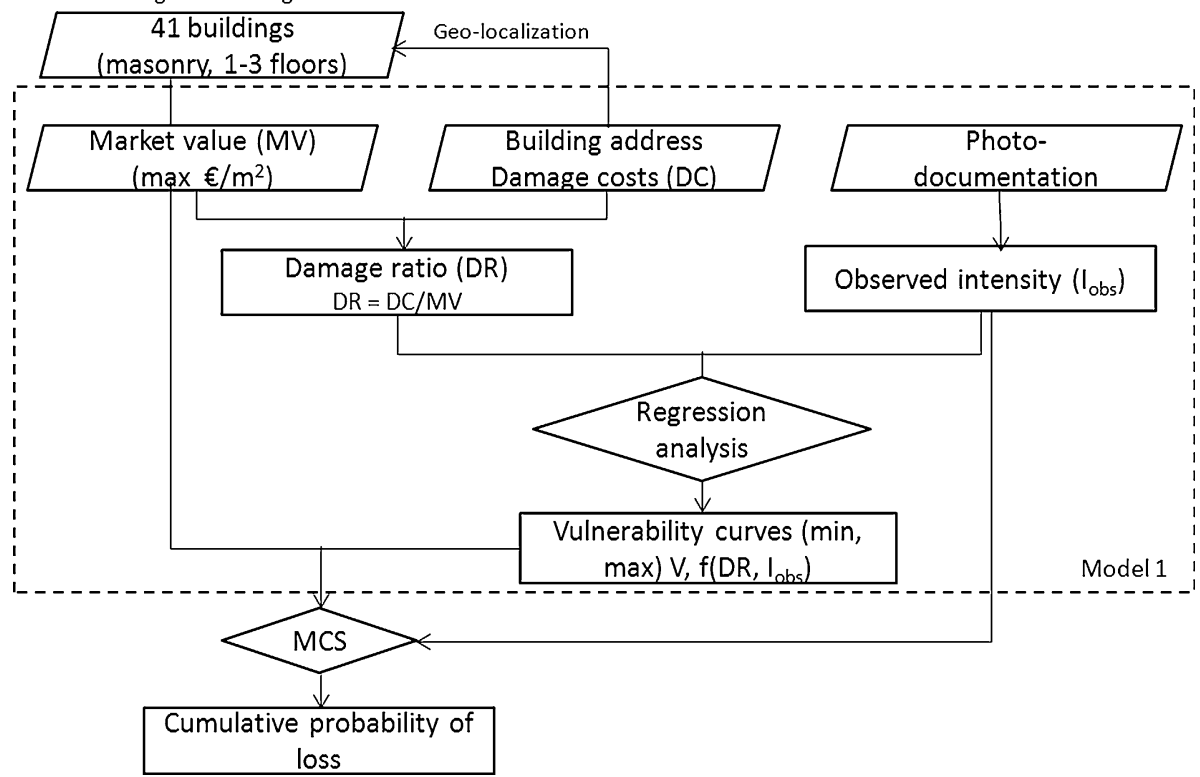

Fig. 3 Flow diagram showing the methodology used to obtain vulnerability curves and cumulative probability of loss at local scale. MCS Monte Carlo sampling

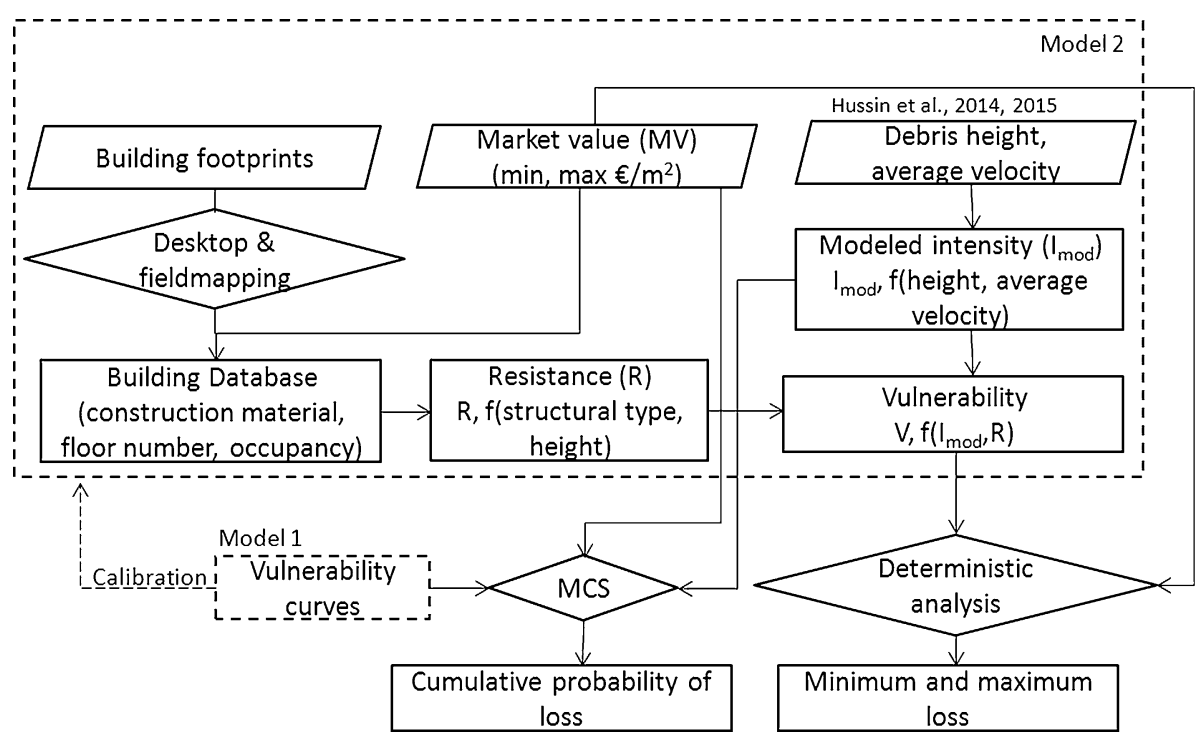

Fig. 4 Flow diagram showing the methodology used to obtain vulnerability values, minimum and maximum loss and cumulative probability of loss at regional scale. MCS Monte Carlo sampling

numerically modeled debris height (Chen et al. 2016; Hussin et al. 2014a, 2015); structural type and building height are used as input for the estimation of building resistance. Both resistance and intensity are expressed in non-dimensional terms and used to compute an 
average vulnerability per building. In a second step, the obtained vulnerability values are used together with the market value to calculate the minimum and maximum loss for each building in the study area, from which a total (minimum and maximum) loss per commune is determined.

Finally, the vulnerability curves developed in Model 1 are applied at regional scale, and loss simulation results are compared with those obtained using vulnerability Model 2. In addition, a subset of the building stock is used to investigate differences in input data and vulnerability models. This work contributes to the risk assessment of debris flow hazard in Fella River valley together with other studies performed within the CHANGES FP7 Project. $^{1}$

\subsection{Building database}

Physical vulnerability assessment requires detailed and up-to-date, geo-localized information about the exposed elements at risk (Schwendtner et al. 2013; van Westen et al. 2006). Thus, the data that were needed to evaluate the resistance and value of buildings in the Fella River valley were inventoried through desktop mapping and field work. A building footprint map with basic attribute information was initially provided by the Civil Protection of the FVG Region. Later, Google Earth and Google Street View image interpretation, as well as field work, was used to acquire detailed information about building characteristics such as occupancy type, material of construction and number of floors.

The monetary value of buildings was obtained as standard minimum and maximum market price (Euros $/ \mathrm{m}^{2}$ ) corresponding to each building type and cadastral zone from the Real Estate Observatory of the Italian Revenue Agency (Osservatorio del Mercato Immobiliare, Agenzia delle Entrate, 2013). The prices were obtained for the second semester of 2013 and adjusted for the effect of inflation using the Italian Consumer Price Index (ITCPI 2005). In this study, the reconstruction/rehabilitation cost was not available; therefore, we decided to use official market values which are easily accessible even for large areas (regional scale) and updatable in further studies. A similar approach was used by Blahut et al. (2014) to estimate the direct loss to debris flows of private properties in Valtellina di Tirano, Italy. The drawback of using these values is the fact that they reflect not only the value of the building, but also the price of the lot, and therefore, they are more sensitive to market fluctuations. Thus, the calculated loss estimations should be considered relevant only for the time of the analysis. To approximate the difference between the market value of a building and its reconstruction/rehabilitation cost, we compared the unit value of single residential houses with similar buildings in analogous socioeconomic contexts.

Finally, the database containing 4778 buildings was stored and processed in a GIS vector data model. In this study, only residential buildings of various occupancy types (apartment building, holiday apartment, house, etc.) are used for the assessment of vulnerability and direct economic loss. More information about the general characteristics of the regional building stock is presented in Chen et al. (2016).

Detailed damage information in the aftermath of the 2003 disaster event was available only for a limited number of buildings. This was collected as photo-documentation, damage cost reports and testimonies from local authorities, Geological Service and Civil

\footnotetext{
${ }^{1}$ CHANGES Project (Changing Hydro-meteorological Risks as Analyzed by a New Generation of European Scientists), Marie Curie Initial Training Network, FP7/2011-2014.
} 
Protection of the FVG Region. Given the scarcity of damage documentation, empirical evidence was used to assess vulnerability of residential buildings only in MalborghettoValbruna commune, as described below.

\subsection{Empirical vulnerability assessment (Model 1)}

Vulnerability curves represent quantitative expressions of the relationship between hazard intensity and the expected damage degree of an element at risk. Intensity is usually estimated using one (rarely two or more) spatially distributed parameter(s) describing the destructive capacity of the process (Hungr, 1997) (e.g., for debris flows: average velocity, impact pressure, accumulation height). In this study, height of accumulated material is used as intensity proxy. Although it may not be the most relevant debris flow intensity descriptor, it is regularly used in empirical studies, since it is directly visible in the field and easy to interpret by decision makers (Quan Luna et al. 2011).

\subsubsection{Process intensity estimation using damage photo-documentation}

In a first step, photo-documentation of damaged structures and high-resolution aerial images were used to estimate the debris flow height. This method was developed and applied for similar processes by Papathoma-Köhle et al. (2012) in a well-documented case study in South Tyrol, Austrian Alps. The debris flow intensity was estimated by visually measuring the maximum deposit height against the upstream building wall (Fig. 3). Photodocumentation was acquired 1-3 days after the event (August 30-September 1, 2003) by the Civil Protection of FVG Region. Although a few photographs were difficult to assess, it was generally possible to estimate the height of the material and make observations about its nature (e.g., debris type and size, matrix granulometry). Figure 5 illustrates the differences in debris height between the upslope and the downslope part relative to a building, as well as the size and nature of the accumulated material. Depending on the position of the camera and the number of photographs per building, this situation may represent a source of error in measurement. It should also be noted that the observed debris height may not entirely correspond to the surge that caused the building damage, due to, for example, subsequent erosion.
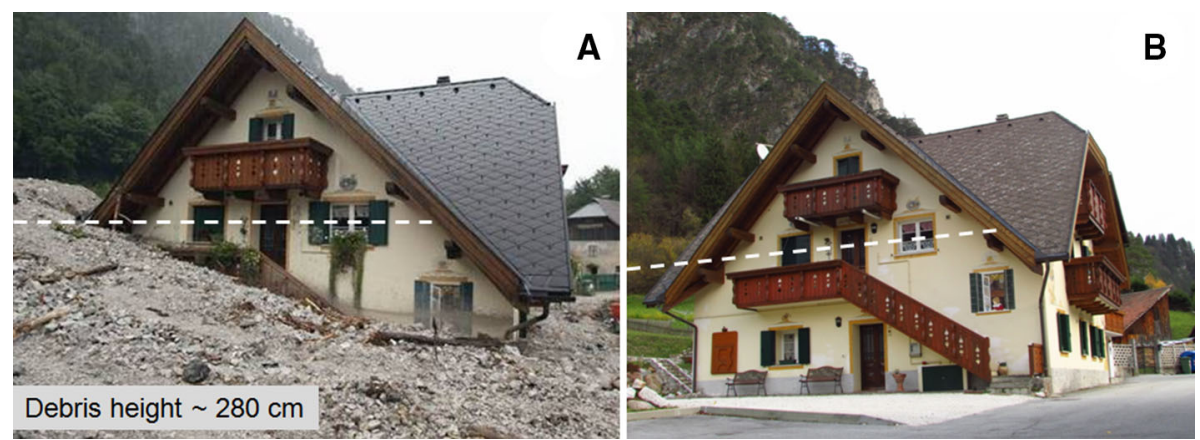

Fig. 5 Building impacted by debris flow (A) 1 day after the August 2003 event and (B) during the field work campaign in 2013 


\subsubsection{Calculation of damage ratio}

Studies on vulnerability of buildings to debris flows vary not only in terms of the use of various intensity proxies, but also due to different expressions of damage degree. PapathomaKöhle et al. (2011) presented a list of vulnerability expressions, such as monetary loss, damage states or a combination of resistance (susceptibility) factors, which vary greatly as a consequence of data availability and scope of analysis. In this study, vulnerability is calculated as the ratio between the reported damage costs of a given building and its monetary value. The building monetary value was obtained by multiplying the maximum market value (Euros $/ \mathrm{m}^{2}$ ), provided by the Real Estate Observatory of the Italian Revenue Agency, with the floor space (equal to the area multiplied by the number of floors). The maximum market value of single-house residential buildings in Malborghetto-Valbruna is equal to $1000 € / \mathrm{m}^{2}$. This value is comparable with the reconstruction/rehabilitation value (i.e., $1153 € / \mathrm{m}^{2}$ ) of similar buildings in analogous socioeconomic regions, as for example in the Autonomous Province of Bolzano/Bozen, South Tyrol (Papathoma-Köhle et al. 2012).

Damage cost data were obtained from the Malborghetto-Valbruna municipality. These represent paid-out monetary compensation ranging from 75 to $90 \%$ of the total loss, for damaged and destroyed buildings, as stated by the Decree No. 107/CD/2004, from May, 6 2004; from these values, a total damage cost was calculated. The reported losses were assessed separately for the building structure, technical costs (e.g., expenses related to cleaning debris material, sludge) and interior assets. In this study, we consider only the vulnerability and losses associated with the building envelope (structural damage).

The quality of the collected information and assumptions made to calculate the damage ratio resulted in a number of inaccuracies. The main errors might stem from the use of building market value as proxy for the reconstruction/rehabilitation value and the geolocalization of buildings based on the address. We also identified one mismatch between the reported costs and the building's damage state.

\subsubsection{Quantification of vulnerability}

To generate vulnerability curves, all buildings were represented as points in a two-dimensional space with intensity values on the $x$-axis and damage ratio on the $y$-axis. During the regression analysis, a high scatter in the data set was observed. One way to overcome this issue was to characterize the entire data set by using a type of distribution concordant with the level of knowledge, and for which the parameters are easiest to determine. In this study, a triangular cumulative function was used to represent the range of plausible vulnerability values. The advantage of this function is that it performs well even if little is known about the parameters outside the approximate estimate of its three known values (Haimes 2009). Moreover, it fulfills the mathematical requirements of a vulnerability function, i.e., degree of loss between 0 and 1 , and is monotonic increasing with the interval of the explaining variable (Papathoma-Köhle et al. 2012). The triangular cumulative function $(\mathrm{CF})$ is defined mathematically as shown in Eq. 1:

$$
V(I)= \begin{cases}0, & I<a \\ \frac{(I-a)^{2}}{(b-a)(c-a)}, & a \leq I \leq c \\ 1-\frac{(b-I)^{2}}{(b-a)(b-c)}, & c<I \leq b \\ 1, & I>b\end{cases}
$$


where $V$ is the vulnerability, $I$ the intensity, $a$ is the lowest intensity value (under which no damage is expected), $b$ is the highest intensity value, and $c$ is an intensity value varying between $a$ and $b$ and controlling the location of the inflection point. These values are obtained through curve fitting at the upper- and lowermost boundaries of the scattered data set. Equation 1 is used as input in regression analysis to generate minimum and a maximum vulnerability curves which envelop the data set. To simulate the scatter of the data set between the two vulnerability limits, a uniform distribution can be selected to characterize the space between them. The uniform cumulative distribution function (CDF) is defined mathematically as shown in Eq. 2:

$$
V(X)= \begin{cases}0, & X<a \\ \frac{X-a}{b-a}, & a \leq X<b \\ 1, & X \geq b\end{cases}
$$

where $a$ and $b$ represent the minimum and the maximum vulnerability values (limits) calculated using Eq. 1, and $X$ is a random variable uniformly distributed between them. Finally, the minimum and maximum vulnerability curves defined by the probability distributions and their parameters are used as input in the next phase of direct loss calculation (Sect. 4.4).

\subsection{Parametric vulnerability assessment (Model 2)}

Physical vulnerability of a building can also be calculated based on a set of factors (indicators) that reflect its capacity to withstand the impact of a hazard with a given intensity. For example, Du et al. (2014) used the structural type, ratio of service years to design service life and the difference between the flow direction and the longitudinal direction of the structure to calculate its vulnerability to debris flows. Such a model (called in this study parametric) is useful in areas where vulnerability curves are missing or for regional-scale assessments where the heterogeneity of buildings with the same occupancy and structural type is high.

In this paper, a conceptual vulnerability model was adapted from Li et al. (2010). The authors calculated the average vulnerability as a function of intensity-to-resistance ratio:

$$
V= \begin{cases}2 \frac{I^{2}}{R^{2}} & \frac{I}{R} \leq 0.5 \\ 1.0-\frac{2(R-I)^{2}}{R^{2}} & 0.5<\frac{I}{R} \leq 1.0 \\ 1.0 & \frac{I}{R}>1.0\end{cases}
$$

where $I$ is the hazard intensity associated with the exposed element at risk, and $\mathrm{R}$ is the resistance ability of the element to withstand the landslide. Both intensity and resistance are expressed in non-dimensional terms. Building resistance $(R)$ to landslide hazard is defined in this paper using the function indicated by Li et al. (2010):

$$
R=\left(\xi_{\mathrm{STR}} \times \xi_{\mathrm{SHT}}\right)^{\frac{1}{2}}
$$

where $\xi_{\mathrm{STR}}$ is the structural typology factor (represented by the material of construction), and $\xi_{\text {SHT }}$ is the building height factor (represented by the number of floors). These two factors were selected because it was possible to collect information related to them over the 
entire area, and they have been identified among the most relevant in previous studies (Silva and Pereira 2014; Uzielli et al. 2015). Through field work and desktop mapping, the following building categories were defined: wood single-story and low-rise (WO1, WO2); masonry single-story, low-rise and medium-rise (MA1, MA2, MA3); and reinforced concrete single-story, low-rise and medium-rise ( $\mathrm{RC} 1, \mathrm{RC} 2, \mathrm{RC} 3, \mathrm{RC} 4)$. A weight was assigned to each resistance factor based on literature survey and critical analysis of the values adopted by Li et al. (2010). Finally, resistance was computed for each building as shown in Eq. 4.

\subsubsection{Process intensity estimation using dynamic runout modeling}

The hazard intensity $(I)$ is calculated by:

$$
I=0.1 \cdot D_{\mathrm{dpt}}
$$

where $I$ is debris flow intensity and $D_{\text {dpt }}$ is the debris height (measured in $\mathrm{cm}$ ) obtained by Hussin et al. (2014b) using dynamic runout modeling. The model outputs were minimum, average and maximum runout maps with debris heights for four a priori defined hazard event scenarios. According to Chen et al. (2016), the August 2003 event corresponds to a major hazard event scenario, with a return period (RP) of around 133 years and within the 100-500 RP range. Thus, the maximum debris flow runout map was selected to perform the vulnerability assessment at regional scale. A detailed description of model parameterization and spatial probability calculation is provided in Hussin et al. (2015).

Li et al. (2010) proposed that in addition to debris flow height, average velocity can be used to estimate debris flow intensity. Hussin et al. (2014a) simulated landslide average velocities (and debris heights) for a post-August 2003 scenario in a representative sub-catchment in the Fella River valley. The authors found that that the maximum velocity near houses was varying between 1.8 and $3.9 \mathrm{~m} / \mathrm{s}$. To improve the regional analysis with the addition of this parameter, flow velocity needs to be assessed at landslide or sub-catchment level over the entire study area. However, such an endeavor requires significant time, data and computational resources, which are rarely available even for smaller study areas. For this reason, and also to enhance the comparison of modeling results with those obtained in empirical approaches, we decided to use only accumulation height as intensity proxy for debris flows (Eq. 5). In order to reduce the uncertainty in vulnerability estimates, future studies should incorporate additional parameters such as impact pressure or average velocity in the analysis.

\subsection{Loss estimation}

In this study, we assess the direct economic loss to residential buildings affected by the August 2003 debris flow event with a return period of 100-500 years (Chen et al. 2016). Loss is calculated for each exposed building (polygon features in the GIS) as the product between its physical vulnerability and market value (Silva and Pereira 2014):

$$
\text { Loss }=\mathrm{PV} \cdot \mathrm{MV}
$$


where PV represents physical vulnerability (non-dimensional term), and MV is the market value (measured in Euro). Two different approaches are used to express economic loss starting from this mathematical relation: (1) using continuous values illustrated as cumulative probability of loss, and (2) discrete (minimum and maximum) values of loss.

The former approach is applied initially at local scale using the maximum market value, the observed debris flow height and the associated minimum and maximum vulnerability value (see Fig. 3). For example, the vulnerability of a given masonry building impacted by a debris flow front with a height of $2.8 \mathrm{~m}$ may vary between 0.27 and 0.89 , according to the empirical analysis results (Model 1). A value between these minimum and maximum limits is then randomly selected and multiplied with the maximum market value to obtain a direct loss value. This process is iteratively performed in MATLAB ${ }^{\circledR}$ in 3000 iterations, and a cumulative probability curve of loss is plotted for the entire building stock. The result illustrates graphically the probability of being above or below a particular loss value, or of being within, or outside, a particular loss range. It should be noted that the probability in this context does not refer to the temporal probability of the debris flow event. To calculate the loss at regional scale using the same approach, we assumed that the vulnerability curves generated at local scale are representative for the residential building stock in Fella River valley. Therefore, the same methodological steps as described above were employed for the 721 buildings (see Fig. 4), with the difference that modeled intensities were used (Hussin et al. 2014b) instead of observed ones.

Finally, to express direct losses in discrete values, we took into account the vulnerability values obtained at regional scale (using Model 2), and the minimum and maximum market values. The loss was calculated according to Eq. 6 and expressed quantitatively as minimum and maximum loss for each building in the study area.

\section{Results}

\subsection{Building characteristics}

The application of the methodological framework is tested in Fella River valley, in the northeastern Italian Alps. In this study area, the majority of the 4778 buildings $(81.3 \%)$ are residential, out of which 721 were exposed to maximum modeled debris flow heights associated with the August 2003 event. The latter were obtained by intersecting the debris flow intensity map with the elements at risk map. From these, at least $26 \%$ are seasonal (if we consider that holiday apartments and cabins are not occupied throughout the year), and $33 \%$ are residential storage structures (garages and sheds). Buildings with mixed land use like commercial-residential buildings represent $0.6 \%$ of the total building stock, out of which none were exposed to modeled debris flows. Figure 6 summarizes the main characteristics of the exposed structures.

Generally, the affected buildings were located at the contact between the slope and alluvial plain, below or in the immediate vicinity of debris flow channels. Two-thirds of the 721 impacted buildings were 2-3-story masonry houses (41\%) and one-story wooden cabins $(34 \%)$. Buildings constructed with mixed materials represented $17 \%$ from the total, most of which (16\%) were 2-3-story masonry-wood houses. The least impacted were one-story brick sheds $(4 \%)$ and concrete apartment buildings of more than 3 storys height $(3 \%)$. 

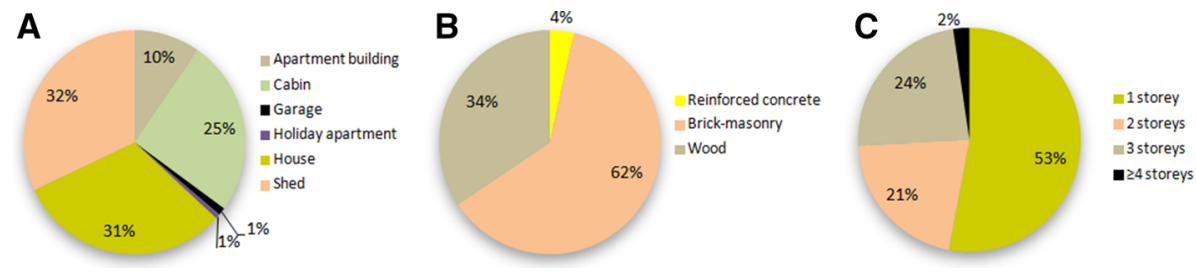

Fig. 6 Main characteristics of the exposed buildings to modeled debris flows representing the August 2003 event. The following attributes are shown: (A) use, (B) material of construction, and (C) number of storys (data set: 721 buildings)

With regard to the data set of 41 buildings used for empirical vulnerability modeling at local scale, it is comprised out of structures of 1-3 storys height, 13 of which are mixed masonry-wood, and 28 are masonry buildings. Figure 7 describes the variability within the data set in terms of material of construction and number of floors against the registered damage costs.

The data show that generally the damage distributions of multi-story and masonrywood buildings are positively skewed, with higher relative frequency of buildings in low damage classes (up to 50,000 €). The damage distribution of masonry buildings on the other hand seems to follow a bimodal uniform pattern. The median damage cost for 2- and 3 -story buildings is 67,494 and $40,227 €$, respectively. There are two buildings of 1 story height in the sample data set; the difference in registered damage costs might be explained (if no other variable is considered) by variations in hazard intensity (see Fig. 8), as both are masonry buildings. In terms of construction material, median damage value for masonry and masonry wood buildings is 64,268 and $24,801 €$, respectively.

Damage to the 41 buildings was caused by different types of impact, depending on the location of buildings and the characteristics of the process. Since debris depth was measured from photographs at building level, Fig. 8 illustrates the spatial pattern of damage costs relative to debris flow intensity only for those buildings for which this information was available. In Malborghetto (Fig. 8A), buildings that were orthogonally facing the main flow direction were (partially) buried by depositional debris of 120-280 cm (for example, in Fig. 5). No buildings in this area collapsed due to dynamic impact pressure. As expected, the further away the building and the larger the angle between the structure and the main flow direction, the lower the damage costs for buildings with similar features. This pattern is more evident in Ugovizza, where buildings located closest to the flow
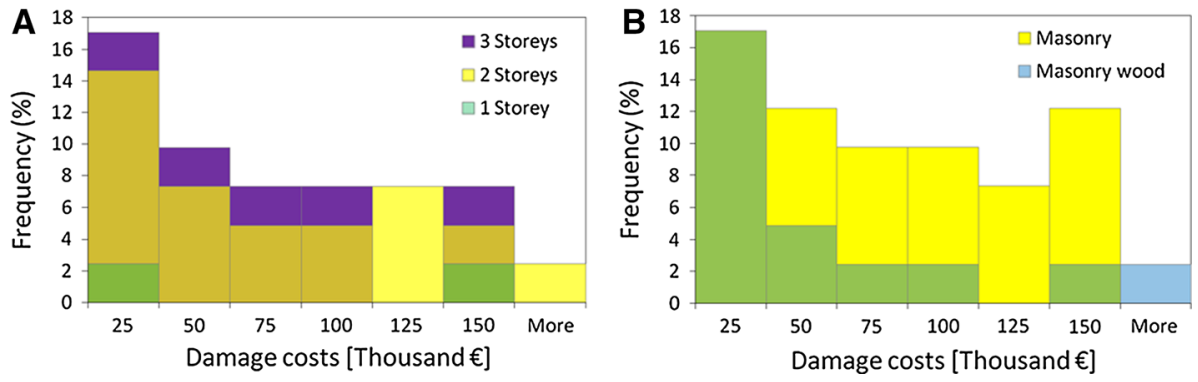

Fig. 7 Frequency plot of (A) material of construction and (B) number of storys of buildings exposed to observed debris flow height in the August 2003 event (data set: 41 buildings). Overlapping bins are green and dark yellow 

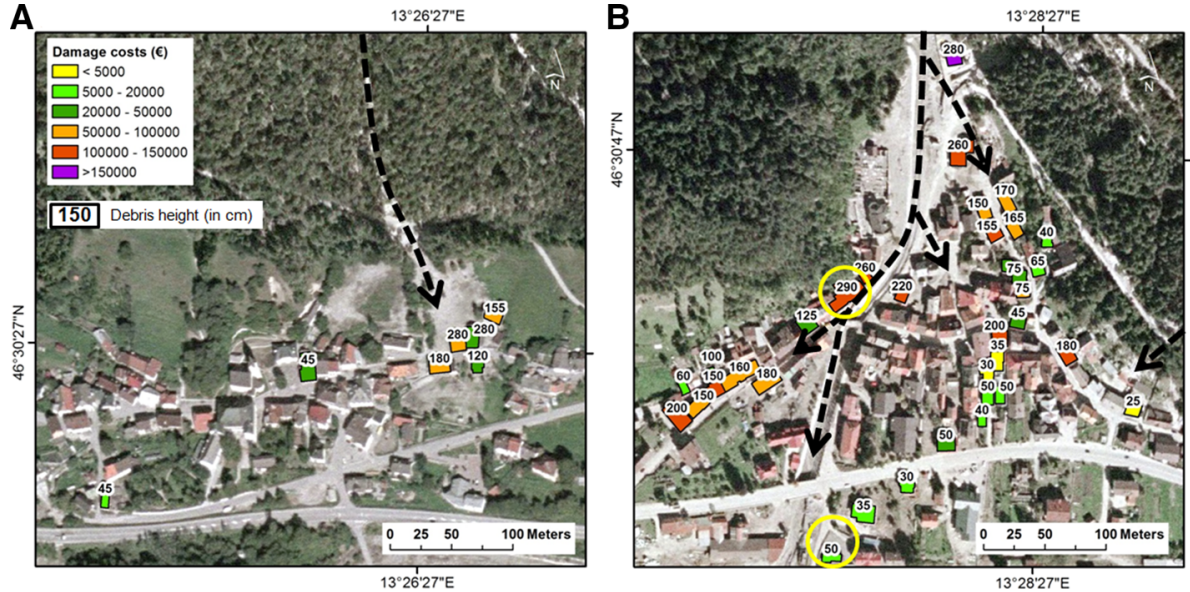

Fig. 8 Spatial pattern of damage costs and debris flow intensity in (A) Malborghetto and (B) Ugovizza. Black arrows indicate flow direction; yellow circles emphasize differences in damage costs/debris height for 1 -story masonry buildings

channel are associated with the highest damage costs and vice versa (Fig. 8B). In this catchment, buildings were affected by direct flow impact, accumulation and abrasion. Moreover, the main flow had a strong flood character (debris flood) with high sediment concentration and secondary debris flows coming from lateral slopes carrying material with lower water content. It should be noted that due to the lack of damage information, not all affected buildings in the two impacted areas were mapped.

\subsection{Building vulnerability assessment using Model 1}

The methodology for vulnerability assessment at local scale is based on the generation of minimum and a maximum vulnerability curves from the empirical data set described above. Based on evidence presented in photo-documentation and damage reports, two empirical points were rejected from the analysis (red points in black circle in Fig. 9) due to mismatches between reported damage costs and observed impact effects. The parameter values used to calculate the vulnerability curves based on Eq. 1 are presented in Table 1.

Fig. 9 Minimum, average and maximum vulnerability as a function of debris height (data set: 39 buildings; see

"Appendix"). Empirical points are classified according to building value (green $<200 \mathrm{k}$

Euros; orange 200-500 k Euros; red $>500 \mathrm{k}$ Euros). Data artefacts in black circle

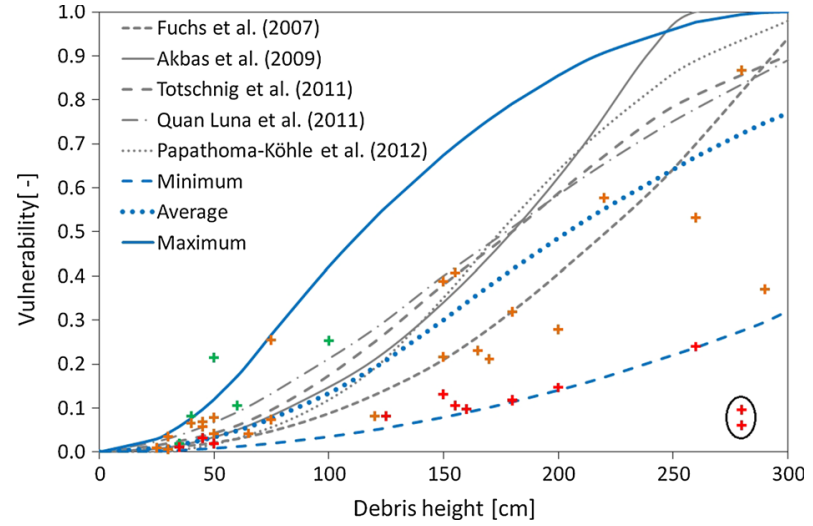


Table 1 Parameter values for Eq. 1 ( $a$-lowest, $b$-highest and $c$-value varying between $a$ and $b$ ) for minimum (min), average (average) and maximum (max) vulnerability curves

\begin{tabular}{lrrr}
\hline Intensity parameter $(\mathrm{cm})$ & Min & Average & Max \\
\hline$a$ & 0 & 0 & 0 \\
$b$ & 300 & 650 & 1000 \\
$c$ & 70 & 185 & 300 \\
\hline
\end{tabular}

Initially, Eq. 2 was tested to simulate the scatter of the data set between the minimum and maximum vulnerability curves. However, relatively better results were obtained using only Eq. 1; therefore, we decided not to use Eq. 2 in the final analysis.

Figure 9 shows that the observations associated with debris heights of 25-100 cm and $\leq 0.25$ degree of loss are well differentiated. However, for medium (100-200 cm) and high $(>200 \mathrm{~cm})$ process intensities, the spread is considerable, although for the latter fewer data points were available. For illustration purposes, an average vulnerability curve was also calculated. This falls within the range of variability of currently existent vulnerability functions, as the ones proposed by Akbas et al. (2009), Fuchs et al. (2007), Quan Luna et al. (2011), Totschnig et al. (2011) and Papathoma-Köhle et al. (2012) for similar buildings in north Italy and south Tyrol (Austria). For intensities up to $135 \mathrm{~cm}$, the average curve coincides relatively well with that of Akbas et al. (2009) and Papathoma-Köhle et al. (2012). For intensities between 135 and $240 \mathrm{~cm}$, it underestimates the values calculated by all authors with the exception of Fuchs et al. (2007). This might be explained by differences in process characteristics such as water-to-solid ratio, type of debris transported (e.g., wooden debris) or flow velocity in different study areas, but it is also related to the incomplete documentation of buildings that were impacted by high-intensity processes in Fella River valley. Other general differences between the six average vulnerability curves are attributed to the number of observation points used to generate them, the intensity assessment method, as well as possible discrepancies in building design and construction techniques.

In economic vulnerability approaches, the size of the building plays an important role as the damage ratio is lower for larger (more valuable) than for smaller (less valuable) buildings exposed to equal intensity levels. To account for this bias in the model, we normalized the intensity against the height of the building; however, the scatter showed no significant change. As the statistical spread of vulnerability values is expected to have an effect on the computation of loss using Monte Carlo sampling, we decided to split the local and regional data sets in three classes depending on the economic value of the building (Table 2; Fig. 10). Minimum and maximum vulnerability curves were then calculated for each class using the parameter values for Eq. 1 presented in Table 2.

The distribution of the damage ratio for the 39 buildings is positively skewed, with mean and median values of 0.17 and 0.1 , respectively. From the total data set, $62 \%$ of the buildings registered a damage ratio below 0.15 (24 buildings) and $8 \%$ (3 buildings) above 0.5 . The latter are related to debris heights of more than $220 \mathrm{~cm}$. Note the absence of buildings within the $0.6-0.75$ and $>0.9$ damage ratio intervals. The latter might be explained by the fact that damage was induced only by infill of debris and subsequent (partial) wall collapse or burial and not complete destruction. 
Table 2 Parameter value for Eq. 1 ( $a$-lowest, $b$-highest and $c$-value varying between $a$ and $b$ ) for minimum $(\min )$ and maximum $(\max )$ vulnerability curves of each building class

\begin{tabular}{|c|c|c|c|c|c|c|}
\hline \multirow{3}{*}{$\begin{array}{l}\text { Local } \\
\text { Regional } \\
\text { Intensity parameter }\end{array}$} & \multirow{2}{*}{\multicolumn{2}{|c|}{$\frac{<200 \mathrm{k} \text { Euro }}{<900 \mathrm{k} \text { Euro }}$}} & \multirow{2}{*}{\multicolumn{2}{|c|}{$\frac{200-500 \text { k Euro }}{900-2 \text { mill. Euro }}$}} & \multirow{2}{*}{\multicolumn{2}{|c|}{$\frac{>500 \mathrm{k} \text { Euro }}{>2 \text { mill. Euro }}$}} \\
\hline & & & & & & \\
\hline & Min & $\operatorname{Max}$ & Min & $\operatorname{Max}$ & Min & $\operatorname{Max}$ \\
\hline$a$ & 0 & 0 & 0 & 0 & 0 & 0 \\
\hline$b$ & 550 & 300 & 800 & 550 & 1000 & 800 \\
\hline$c$ & 80 & 70 & 150 & 80 & 300 & 150 \\
\hline
\end{tabular}
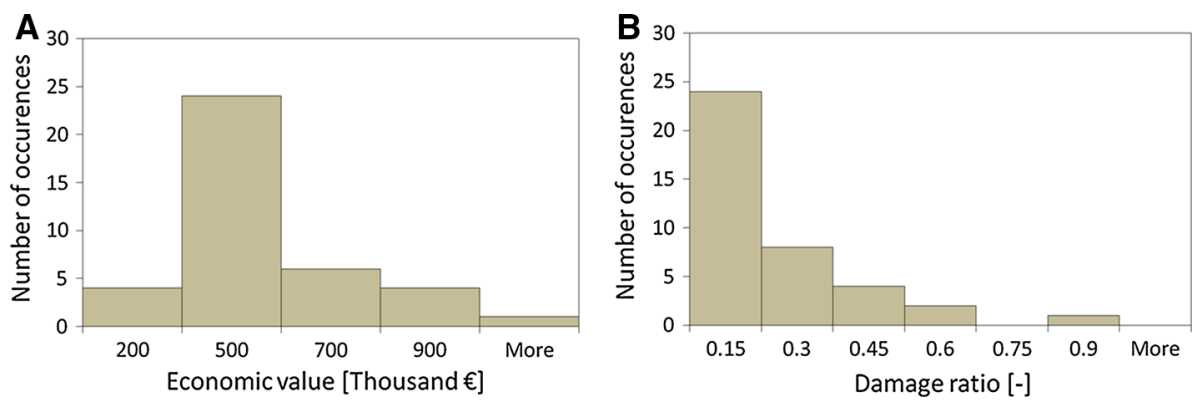

Fig. 10 Histograms of (A) economic value and (B) damage ratio of buildings exposed to observed debris flow height in the August 2003 event (data set: 39 buildings; see "Appendix")

\subsection{Building vulnerability assessment using Model 2}

The methodology for vulnerability assessment at regional scale is based on the application of a conceptual model that takes into account the structural typology (represented by the material of construction) and height (represented by the number of floors) to determine a building's resistance to a given hazard intensity level. Li et al. (2010) proposed a set of theoretical (non-dimensional) values of resistance for structural typology and height based on engineering judgment (Tables 3, 4).

Initially, these theoretical values were used as input to the model, and the resulting vulnerability estimates were compared with those obtained in other empirical studies. In a second step, the theoretical values of resistance were calibrated against the results obtained

Table 3 Values for structural typology resistance factor $\left(\xi_{\mathrm{STR}}\right)$

\begin{tabular}{llll}
\hline & Structural typology $^{\mathrm{a}}$ & This study & Li et al. (2010) \\
\hline WO & Wood & 0.25 & 0.2 \\
MA & Masonry & 0.90 & 0.8 \\
RC & Reinforced concrete & 1.95 & 1.3
\end{tabular}

${ }^{a}$ Mixed structural types (e.g., masonry-wood) are counted in the category of the main material of construction (e.g., masonry) 
Table 4 Values for building height resistance factor $\left(\xi_{\mathrm{SHT}}\right)$

\begin{tabular}{llll}
\hline Height & Number of floors & This study & Li et al. (2010) \\
\hline Single-story & 1 & 0.4 & 0.1 \\
Low-rise & 2 & 0.85 & 0.4 \\
Medium-rise & 3 & 1 & 0.9 \\
Medium-rise & 4 & 1.2 & 0.9 \\
\hline
\end{tabular}

with empirical Model 1. Figure 11 indicates the change in coefficient of determination from $R^{2}=0.39$ to 0.52 for a sample data set of 20 buildings, as a result of modifying the values of resistance in Model 2.

As expected, the difference between the vulnerability estimates obtained with Model 2 and those obtained in other empirical studies reduced after the calibration. For the ease of comparison, the average curve developed with Model 1 and other curves existing in the literature are plotted together with the results of Model 2, in Fig. 12. This illustrates the range of vulnerability values for wooden (WO), masonry (MA) and reinforced concrete (RC) buildings of 1-4 storys height associated with debris flow intensities of maximum $300 \mathrm{~cm}$. The results generally suggest that the higher the wall resistance, the lower the expected damage degree. Single-story buildings are significantly more vulnerable than multi-story buildings of the same structural type, possibly due to the different distribution of openings (doors and windows) that allow the material to enter the building. This, however, is highly dependent on the flow dynamic pressure, as the opening may actually decrease the probability of wall failure by reducing the applied pressure (Mavrouli et al. 2014).

The empirical curve developed with Model 1 coincides up to a debris height of $130 \mathrm{~cm}$ with the vulnerability values of medium-rise masonry buildings obtained in Model 2 . This seems to suggest that the latter overestimates the degree of loss for higher process intensities. However, the dissimilarity is due to the different methods of intensity assessment and scales of analysis (i.e., Model 1, based on debris height observations; Model 2, using regional runout modeling).

\subsection{Direct loss estimation using vulnerability Model 1}

Vulnerability values estimated with Model 1 are further used together with building market values to calculate the direct economic loss at local and regional scale. The total reported
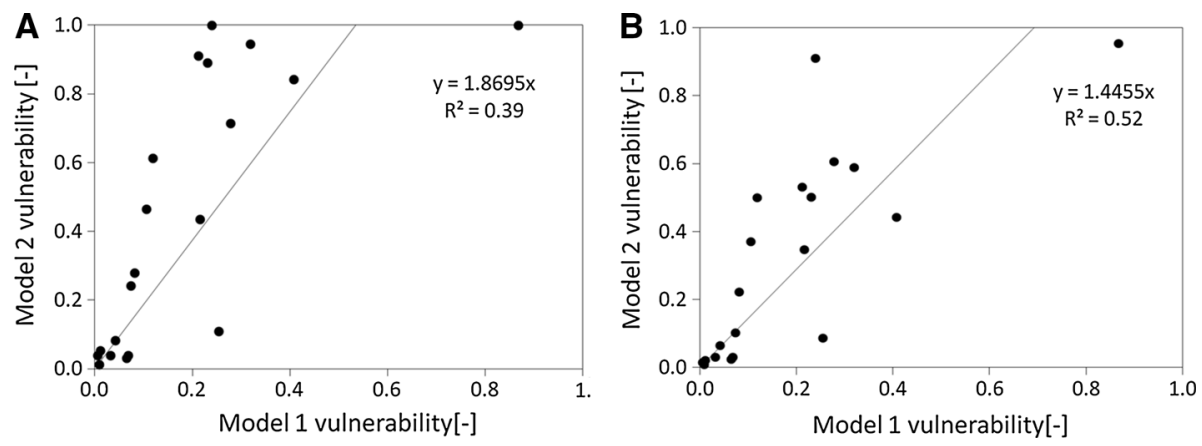

Fig. 11 Model 1 versus Model 2 vulnerability using (A) theoretical and (B) modified values of resistance for Model 2 (data set: 20 buildings). Observed debris heights were used in both models 


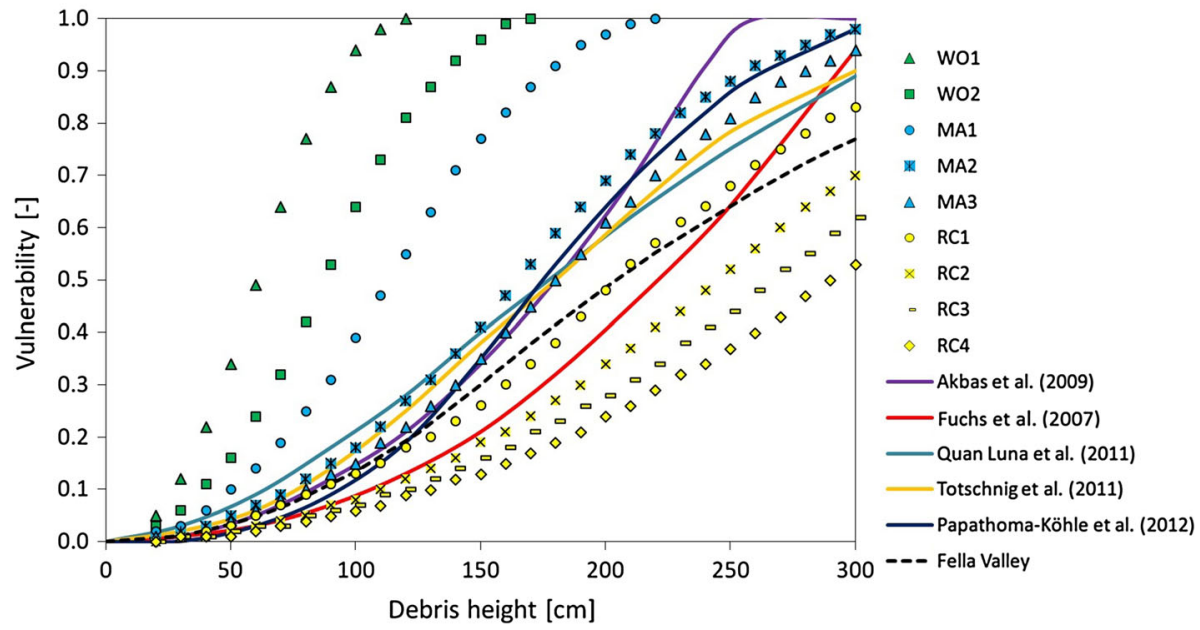

Fig. 12 Vulnerability values of wooden (WO), masonry (MA) and reinforced concrete (RC) buildings of 1-4 storys as a function of debris height. Average vulnerability curve obtained with Model 1 and from the literature is indicated

damage costs for the 39 buildings in Malborghetto-Valbruna were equal to 2.42 million Euros. It should be noted that this amount does not reflect the technical costs or losses induced to interior assets, such as furniture and electronic equipment. The maximum value at risk for the same exposed buildings was 16 million Euros resulting in a direct economic loss of $14.2 \%$ (Fig. 13). According to the simulations, there is a $10 \%$ probability of having a direct economic loss below 2.37 million Euros and a $90 \%$ probability that the loss is below 2.6 million Euros.

To compute the cumulative probability of loss for the regional building stock, we used the intensity parameter values presented in Table 2 and the maximum market value of the buildings exposed to modeled debris flows representing the August 2003 event. The results of the simulation show that there is an $80 \%$ probability that the loss is between 44.3 million Euros and 45.4 million Euros for the exposed regional building stock.

\subsection{Direct loss estimation using vulnerability Model 2}

Direct loss was also calculated using vulnerability Model 2 for the entire study area. Figure 14 illustrates the maximum loss for buildings in Malborghetto and Ugovizza exposed to modeled debris heights. The maximum losses in both areas vary between less than $45 \mathrm{k}$ Euros and over $500 \mathrm{k}$ Euros, with higher values associated with debris height over $200 \mathrm{~cm}$. A comparison of reported damage costs and estimated maximum losses for buildings exposed in both sub-catchments generally indicates an overestimation of losses at building level (between 13 and $178 \%$ ) for 14 out of 20 buildings. The reason for this might be that in Ugovizza the small debris flows coming from the side slopes interacted with the main flow which had a flash-flood character. This might have resulted in lower debris material accumulation than those estimated by the runout model.

Figure 15 indicates the range of total loss values (minimum and maximum) per building type. Given the high proportion of multi-story masonry buildings in the study area, they registered an estimated loss between and 7.7 and 10.9 million Euros for MA2, and 19.1 and 

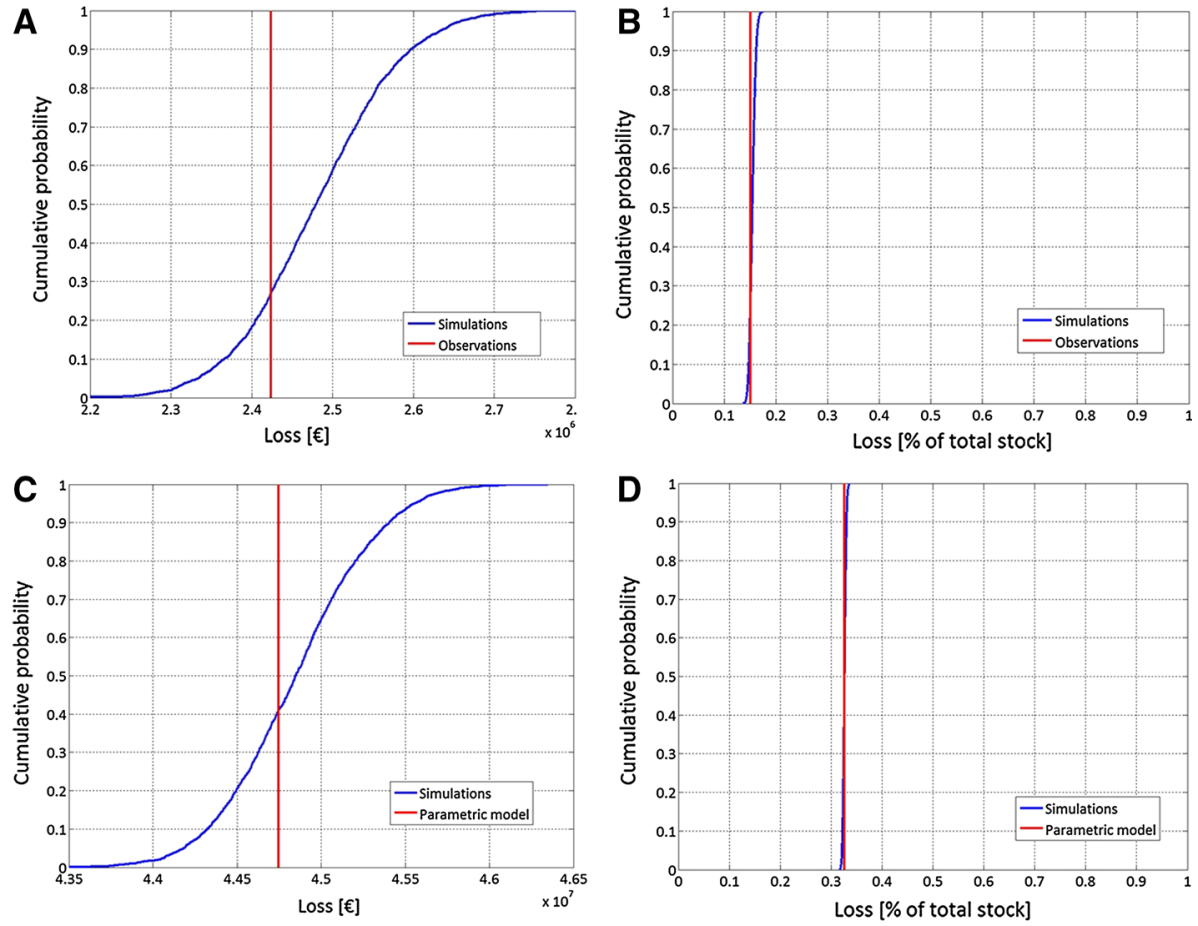

Fig. 13 Cumulative probability of loss for buildings affected by debris flows in the aftermath of the August 2003 event. Absolute and relative values of loss at (A, B) local and (C, D) regional scale. 3000 iterations have been computed

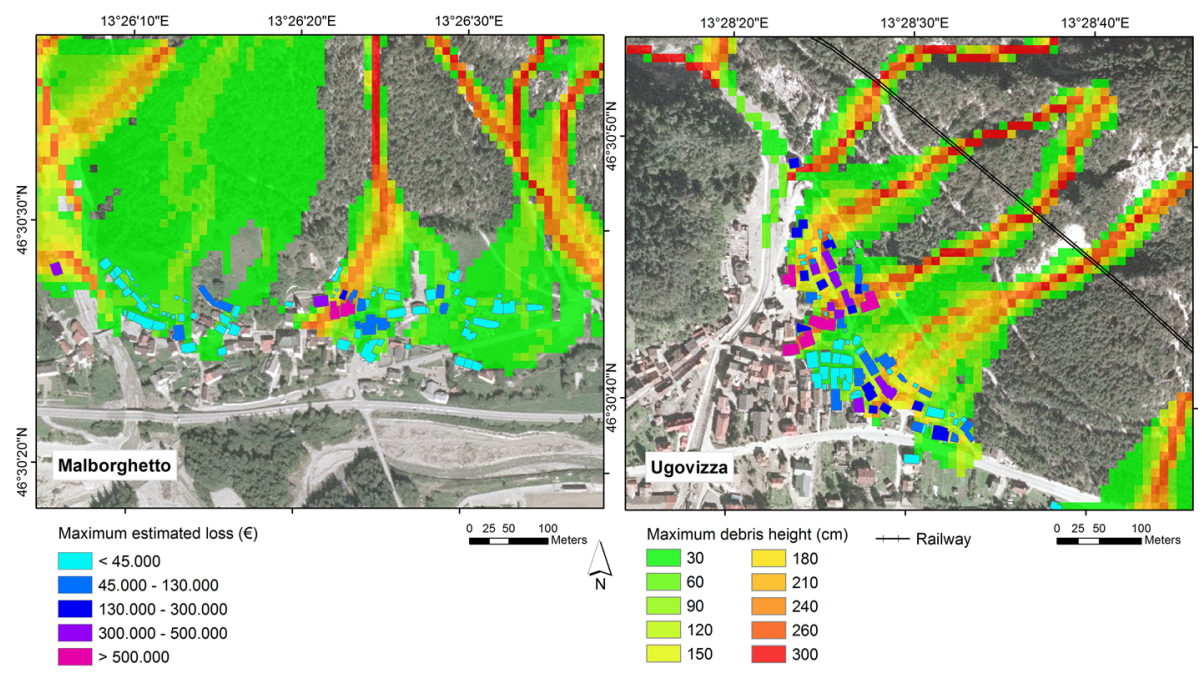

Fig. 14 Maximum direct loss estimated based on modeled debris heights and vulnerability Model 2 
26.9 million Euros for MA3. A relatively significant loss value (between 1.8 and 2.6 million Euros) for a reduced number of buildings is associated with 4-story high RC buildings; these are apartment buildings located in Pontebba and Malborghetto-Valbruna.

Due to the limited damage information, a validation of the results at building level for the entire study area was not possible. However, zone-specific sums of damage costs were available from the Civil Protection of FVG Region. Table 5 presents a comparison between (maximum) modeled and documented monetary losses at commune level. The data show a relatively good estimation of damage costs for Pontebba and MalborghettoValbruna, the municipalities that suffered most of the losses in the study area.

A different situation is registered for Dogna and Tarvisio, where the modeled losses are underestimating or overestimating, respectively, the observed damage costs. Two explanations can be given for this: (1) The study site does not encompass the entire administrative area of the two communes (as opposed to the former ones); therefore, the building sample size is underestimated; (2) errors due to model transformations and simplifications. Table 5 also shows that the highest relative uncertainty (computed as the ratio between the maximum modeled loss and the documented loss) is associated with Dogna and Tarvisio communes.

\section{Discussion and conclusions}

Two vulnerability models were used in this study, each having limitations and introducing a number of uncertainties. The first vulnerability model was based on developing vulnerability curves from empirical data. The main drawback of this approach is that it is based on scarce process intensity data. Another important issue here is the definition of the damage ratio on the basis of the building value. One of the advantages of this approach is that it enhances the comparison of vulnerability curves developed in different economic regions. The limitation is that due to the heterogeneity of buildings and scale of analysis, rehabilitation/reconstruction values were not available; therefore, an approximation was used (i.e., market value).

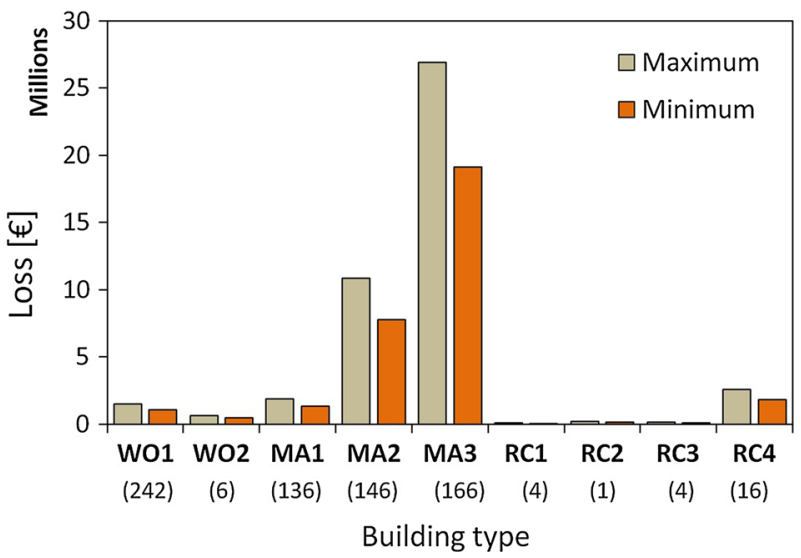

Fig. 15 Direct maximum and minimum loss values per building type in Fella River valley. The number in brackets represents the building class size 
Table 5 Modeled maximum economic loss per commune (absolute and relative values) versus documented damages by the Civil Protection of the FVG Region

\begin{tabular}{|c|c|c|c|c|c|}
\hline Commune & $\begin{array}{l}\text { Documented } \\
\text { (million Euro) }\end{array}$ & $\%$ & $\begin{array}{l}\text { Modeled } \\
\text { (million Euro) }\end{array}$ & $\%$ & $\begin{array}{l}\text { Relative } \\
\text { uncertainty }^{\mathrm{a}}\end{array}$ \\
\hline Malborghetto-Valbruna & 36 & 61 & 25.3 & 57 & 0.7 \\
\hline Pontebba & 18 & 30 & 17.3 & 39 & 1 \\
\hline Tarvisio & 0.5 & 1 & 1.8 & 4 & 3.5 \\
\hline Dogna & 5 & 8 & 0.4 & 1 & 0.1 \\
\hline Total & 59.5 & 100 & 44.7 & 100 & \\
\hline
\end{tabular}

${ }^{a}$ Ratio between the maximum modeled loss and the documented loss

A basic comparison between the results of Model 1 and other empirical curves from the literature shows that the average vulnerability curve developed here falls within the range of variability of the existent ones. Despite this, the wide range of the minimum-maximum curves indicates the level of uncertainty in the input data set.

The large scatter of empirical data is attributed partially to the heterogeneity of process intensity at sub-catchment level. The comparison between observed intensities and resulting damages gave an indication of the complexity and variability of process characteristics in two adjacent sub-catchment areas (e.g., from debris flows with low velocity, small debris clasts, which build up slowly a high wavefront, to high-energy velocity flows and even flash floods). Totschnig and Fuchs (2013) concluded that there is no need to distinguish between different sediment-laden torrent processes when assessing physical vulnerability of residential buildings toward torrent processes (e.g., debris flows, fluvial sediment transport). This study suggests that because of the differences in process characteristics, the use of accumulation height as intensity proxy should be replaced in the future with more relevant parameters like impact pressure or combined with flow velocity. This applies for the regional vulnerability assessment as well, although the spatial scale involves certain modeling challenges.

As demonstrated in previous studies (Alexander 2005; Fuchs 2008; Mavrouli et al. 2014), susceptibility of structures to damage induced by landslides is influenced by a number of technological and physical characteristics, among which structural typology, foundation depth and type, height and age are considered important. The second vulnerability model used in this study is based on a mathematical model that gives the opportunity to incorporate a number of resistance factors in the calculation of vulnerability. However, the values of these factors must be calibrated against empirical data or numerical (physical) modeling results to convey realistic values.

Regarding the regional loss analysis, the underestimation of total economic damages is related to the fact that reported values included losses to commercial and industrial facilities which are not considered in this study; neither are technical costs or damage to interior assets of buildings. Moreover, the analysis was performed using the present building stock and not taking into account the buildings destroyed in the August 2003 event. An integrated risk analysis to multi-hazards in Fella River valley was performed by Chen et al. (2016). The authors estimated that the economic loss associated with the August 2003 event to buildings impacted by debris flows and flash floods was 22.2 million Euros.

The interpretation of vulnerability and loss modeling results requires utmost care and should be done only considering the underlying assumptions and indicated uncertainties. 
One assumption is related to use of building market values as proxy for building reconstruction/rehabilitation costs; another one allowed us to apply the empirical curves developed at local scale in the generation of the cumulative probability of loss at regional scale. Both assumptions increased the level of uncertainty in the results. Other important sources of uncertainty are presented in Table 6. From those partially treated, some are implicitly or explicitly included in the analysis. For example, the cumulative probability of loss (Fig. 13) takes into account explicitly the uncertainty in the vulnerability curves; however, the uncertainty in the process intensity estimates is only implicitly addressed (since no separate probability distribution was used to characterize it).

In order to improve the results obtained with Model 2, future applications can be amended with the use of additional resistance parameters like direction of building with respect to the direction of flow, depth of foundation or type/size building openings. However, one must decide to use only parameters whose variation has the greatest outcome in changing building resistance. This will avoid excessive computation and redundant information. Vulnerability results obtained with Model 1 can be improved by updating the damage database as soon as new information is available, as well as acquiring data about construction costs of different types of buildings. Finally, in order to fully quantify the propagation of errors between the different stages of consequence analysis, a fully probabilistic Monte Carlo simulation can be performed by substituting the range of minimummaximum values with a probability distribution for each variable in the model.

Table 6 Sources of uncertainty in the two-phase methodologies at local and regional scale applied in this study

\begin{tabular}{|c|c|c|c|c|}
\hline Source & Type & Cause & Treatment & Solution \\
\hline \multicolumn{5}{|c|}{ Vulnerability assessment } \\
\hline $\begin{array}{l}\text { Selection of } \\
\text { distribution } \\
\text { function }\end{array}$ & $\mathrm{E}$ & Data set scatter & Partial & Triangular/uniform distributions \\
\hline $\begin{array}{l}\text { Intensity } \\
\text { assessment }\end{array}$ & $\mathrm{E} / \mathrm{A}$ & $\begin{array}{l}\text { Measurement errors/natural } \\
\text { variability }\end{array}$ & Partial & Parametrization of triangular $\mathrm{CF}$ \\
\hline Market value & $\mathrm{E} / \mathrm{A}$ & $\begin{array}{l}\text { Proxy variable for building } \\
\text { reconstruction cost }\end{array}$ & Partial & $\begin{array}{l}\text { Calibration against } \\
\text { reconstruction costs in other } \\
\text { areas }\end{array}$ \\
\hline Sampling error & $\mathrm{E}$ & Data set availability & No & $\begin{array}{l}\text { Collection of additional data; } \\
\text { use of confidence intervals }\end{array}$ \\
\hline \multicolumn{5}{|l|}{ Loss analysis } \\
\hline $\begin{array}{l}\text { Application of } \\
\text { Model } 2\end{array}$ & $\mathrm{E}$ & Testing of theoretical model & No & Validation in another study area \\
\hline $\begin{array}{l}\text { Resistance factors } \\
\text { values }\end{array}$ & $\mathrm{E} / \mathrm{A}$ & $\begin{array}{l}\text { Heterogeneity of building } \\
\text { stock; subjective judgment }\end{array}$ & Partial & $\begin{array}{l}\text { Empirical calibration; modifying } \\
\text { data sampling technique }\end{array}$ \\
\hline $\begin{array}{l}\text { Application of } \\
\text { Model } 1\end{array}$ & $\mathrm{E}$ & Generalization/simplification & No & $\begin{array}{l}\text { Transfer of vulnerability curves } \\
\text { for other building types }\end{array}$ \\
\hline Object value & $\mathrm{E} / \mathrm{A}$ & $\begin{array}{l}\text { Variability due to } \\
\text { heterogeneity of building } \\
\text { stock }\end{array}$ & Partial & Value ranges \\
\hline $\begin{array}{l}\text { Vulnerability } \\
\text { results }\end{array}$ & $\mathrm{E}$ & Propagated errors & No & Monte Carlo simulation \\
\hline
\end{tabular}

Type: $E$-epistemic; $A$-aleatory 
In this study, a multi-scale building vulnerability and loss assessment framework was developed and applied in a study area in the northeastern Italian Alps. In this work, former conceptual models were used in order to identify challenges and possible solutions in their application. The methodological framework is based on the generation of empirical vulnerability curves and vulnerability values for multiple types of buildings, which are then used to calculate the direct economic loss of individual buildings or for a set of building in a given area.

The results in this study indicate that vulnerability Model 1 simulates better the damages observed at local scale than vulnerability Model 2, due to the use of empirical data; however, the application of Model 2 at regional scale seems to be appropriate because of the heterogeneity of the building stock characteristics, which are not considered in Model 1 .

The findings of this research support the idea that in order to obtain realistic vulnerability (and loss) estimates building vulnerability assessment to debris flows must take into account other intensity proxies than depth of accumulation. The variability of building responses to stresses induced by different flow-type processes cannot be explained solely by (post-event) assessment of accumulated material. This also implies that a better investigation of process characteristics is needed.

Although uncertainty was not fully accounted for/quantified in the Monte Carlo simulation, this approach enhanced the understanding of vulnerability model limitations and underlying data errors. Moreover, the expression of uncertainty as value ranges and cumulative probability plots has the advantage of being easy to convey to stakeholders and sufficiently informative to support the formulation of decision criteria, such as maximizing the minimum loss or minimizing the maximum loss (Haimes 2009).

Finally, the results obtained in this study may be used by stakeholder to identify hot spots for future mitigation planning which might lead to a reduction in future economic losses.

Acknowledgments Open access funding provided by the University of Vienna. This work is a part of the CHANGES Project (Changing Hydro-meteorological Risks as Analyzed by a New Generation of European Scientists), a Marie Curie Initial Training Network funded by the European Community, under Grant Agreement No. 263953. The research was partially supported through the Marietta Blau Grant, provided by the Austrian Federal Ministry of Science, Research and Economy (BMWFW). The authors would like to thank the stakeholders in Friuli-Venezia Giulia Region (especially the Civil Protection, Municipality of Malborghetto-Valbruna and Geological Survey) for data sharing and cooperation in the study area. We also like to thank Alessandro Pasuto (CNR-IRPI, Padua) for support in data collection and Simone Sterlacchini (CNR-IDPA, Milano, Italy) for constructive discussions. Finally, we are grateful to the anonymous reviewers for their valuable comments and suggestions on an earlier draft of this paper.

Open Access This article is distributed under the terms of the Creative Commons Attribution 4.0 International License (http://creativecommons.org/licenses/by/4.0/), which permits unrestricted use, distribution, and reproduction in any medium, provided you give appropriate credit to the original author(s) and the source, provide a link to the Creative Commons license, and indicate if changes were made.

\section{Appendix}

See Table 7. 
Table 7 The data set used for the development of the vulnerability curves in Malborghetto-Valbruna, Eastern Italian Alps

\begin{tabular}{|c|c|c|c|c|}
\hline No. & Observed intensity $(\mathrm{cm})$ & Damage costs $(€)$ & Max market value $(€)$ & Damage ratio \\
\hline 1 & 30 & 2282.96 & $383,005.59$ & 0.00 \\
\hline 2 & 25 & 3476.92 & $393,584.87$ & 0.00 \\
\hline 3 & 35 & 3175.80 & $290,340.74$ & 0.01 \\
\hline 4 & 50 & 9725.99 & $500,793.00$ & 0.01 \\
\hline 5 & 35 & $14,800.81$ & $758,351.44$ & 0.01 \\
\hline 6 & 45 & $24,801.87$ & $768,554.12$ & 0.03 \\
\hline 7 & 30 & 9578.43 & $272,759.54$ & 0.03 \\
\hline 8 & 50 & $13,699.39$ & $337,650.66$ & 0.04 \\
\hline 9 & 65 & $13,304.97$ & $316,869.10$ & 0.04 \\
\hline 10 & 45 & $12,539.12$ & $220,694.56$ & 0.05 \\
\hline 11 & 40 & $19,606.13$ & $302,624.68$ & 0.06 \\
\hline 12 & 45 & $30,291.35$ & $445,518.52$ & 0.06 \\
\hline 13 & 75 & $32,154.71$ & $435,839.54$ & 0.07 \\
\hline 14 & 50 & $27,733.81$ & $357,966.19$ & 0.07 \\
\hline 15 & 120 & $33,541.75$ & $411,919.73$ & 0.08 \\
\hline 16 & 125 & $46,914.05$ & $575,967.67$ & 0.08 \\
\hline 17 & 40 & $14,750.95$ & $180,556.70$ & 0.08 \\
\hline 18 & 160 & $71,543.32$ & $731,386.97$ & 0.09 \\
\hline 19 & 60 & $17,826.88$ & $169,869.07$ & 0.10 \\
\hline 20 & 155 & $61,042.29$ & $576,755.61$ & 0.10 \\
\hline 21 & 180 & $90,900.40$ & $776,542.30$ & 0.11 \\
\hline 22 & 180 & $61,377.33$ & $517,487.19$ & 0.11 \\
\hline 23 & 150 & $67,493.97$ & $515,927.80$ & 0.13 \\
\hline 24 & 200 & $133,333.33$ & $910,863.24$ & 0.14 \\
\hline 25 & 170 & $97,828.85$ & $461,865.80$ & 0.21 \\
\hline 26 & 50 & $21,974.40$ & $102,704.41$ & 0.21 \\
\hline 27 & 150 & $85,217.64$ & $394,590.60$ & 0.21 \\
\hline 28 & 165 & $94,185.63$ & $407,992.99$ & 0.23 \\
\hline 29 & 260 & $130,000.00$ & $543,134.94$ & 0.23 \\
\hline 30 & 100 & $46,334.31$ & $183,493.03$ & 0.25 \\
\hline 31 & 75 & $86,155.88$ & $338,833.75$ & 0.25 \\
\hline 32 & 200 & $133,333.33$ & $479,617.97$ & 0.27 \\
\hline 33 & 180 & $115,202.85$ & $361,191.75$ & 0.31 \\
\hline 34 & 290 & $133,333.33$ & $360,307.23$ & 0.37 \\
\hline 35 & 150 & $111,559.44$ & $287,945.90$ & 0.38 \\
\hline 36 & 155 & $102,058.39$ & $250,412.90$ & 0.40 \\
\hline 37 & 260 & $133,333.33$ & $250,595.10$ & 0.53 \\
\hline 38 & 220 & $139,648.32$ & $242,335.83$ & 0.57 \\
\hline 39 & 280 & $177,969.65$ & $205,180.77$ & 0.86 \\
\hline
\end{tabular}




\section{References}

AGS (2007) Practice note guidelines for landslide risk management. Australian Geomechanics Society Landslide Taskforce, Landslide Practice Note Working Group Australian Geomechanics, vol 42, pp 63-114

Akbas SO, Blahut J, Sterlacchini S (2009) Critical assessment of existing physical vulnerability approaches for debris flows. In: Malet JP, Remaitre A, Bogaard T (eds) International conference-landslide processes: from geomorphologic mapping to landslide modelling, 6-7 February 2009, Strasbourg, France, 2009. pp 229-233

Alexander D (2005) Vulnerability to landslides. In: Glade T, Anderson MG, Crozier M (eds) Landslide hazard and risk. Wiley, Chichester, pp 175-198

Birkmann J (2006) Measuring vulnerability to promote disaster-resilient societies: conceptual frameworks and definitions. In: Birkmann J (ed) Measuring vulnerability to natural hazards: towards disaster resilient societies. United Nations University Press, Tokyo, pp 9-54

Blahut J, Glade T, Sterlacchini S (2014) Debris flows risk analysis and direct loss estimation: the case study of Valtellina di Tirano, Italy. J Mt Sci 11:288-307. doi:10.1007/s11629-013-2806-2

Borga M, Boscolo P, Zanon F, Sangati M (2007) Hydrometeorological analysis of the 29 August 2003 flash flood in the eastern Italian Alps. J Hydrometeorol 8:1049-1067. doi:10.1175/jhm593.1

Cardinali $\mathrm{M}$ et al (2002) A geomorphological approach to the estimation of landslide hazards and risks in Umbria, Central Italy. Nat Hazards Earth Syst Sci 2:57-72. doi:10.5194/nhess-2-57-2002

Chen L, van Westen CJ, Hussin HY, Ciurean RL, Turkington T, Chavarro D, Shrestha DP (2016) Integrating expert opinion with modelling for quantitative multi-hazard risk assessment in the Eastern Italian Alps. Geomorphology 273:150-167

Corominas J et al (2014) Recommendations for the quantitative analysis of landslide risk. Bull Eng Geol Environ 73:209-263. doi:10.1007/s10064-013-0538-8

Crozier MJ, Glade T (2005) Landslide hazard and risk: issues, concepts and approach. Landslide hazard and risk. Wiley, Chichester, pp 1-40. doi:10.1002/9780470012659.ch1

Cutter SL, Boruff BJ, Shirley WL (2003) Social vulnerability to environmental hazards. Soc Sci Q 84:242-261. doi:10.1111/1540-6237.8402002

Du J, Yin K, Lacasse S, Nadim F (2014) Quantitative vulnerability estimation of structures for individual landslide: application to the Metropolitan Area of San Salvador, El Salvador. Electron J Geotech Eng 19:1251-1264

Eidsvig UMK, Papathoma-Köhle M, Du J, Glade T, Vangelsten BV (2014) Quantification of model uncertainty in debris flow vulnerability assessment. Eng Geol 181:15-26. doi:10.1016/j.enggeo.2014. 08.006

Fell R, Ho KKS, Lacasse S, Leroi E (2005) A framework for landslide risk assessment and management. In: Hungr O, Fell R, Couture R, Eberhardt E (eds) Landslide risk management. Taylor and Francis, London, pp 3-26

Fuchs S (2008) Vulnerability to torrent processes. Risk Anal 6:289-298. doi:10.2495/risk080291

Fuchs S (2009) Susceptibility versus resilience to mountain hazards in Austria-paradigms of vulnerability revisited. Nat Hazards Earth Syst Sci 9:337-352. doi:10.5194/nhess-9-337-2009

Fuchs S, Heiss K, Hübl J (2007) Towards an empirical vulnerability function for use in debris flow risk assessment. Nat Hazards Earth Syst Sci 7:495-506

Fuchs S, Kuhlicke C, Meyer V (2011) Editorial for the special issue: vulnerability to natural hazards-the challenge of integration. Nat Hazards 58:609-619. doi:10.1007/s11069-011-9825-5

Fuchs S, Ornetsmüller C, Totschnig R (2012) Spatial scan statistics in vulnerability assessment: an application to mountain hazards. Nat Hazards 64:2129-2151

Glade T (2003) Vulnerability assessment in landslide risk analysis. Erde 134:123-146

Glade T, Crozier MJ (2005a) The nature of landslide hazard impact. In: Landslide hazard and risk. Wiley, Chichester, pp 41-74. doi:10.1002/9780470012659.ch2

Glade T, Crozier MJ (2005b) A review of scale dependency in landslide hazard and risk analysis. In: Landslide hazard and risk. Wiley, Chichester, pp 75-138. doi:10.1002/9780470012659.ch3

Godfrey A, Ciurean RL, van Westen CJ, Kingma NC, Glade T (2015) Assessing vulnerability of buildings to hydro-meteorological hazards using an expert based approach—an application in Nehoiu Valley. Romania Int J Disaster Risk Reduct 13:229-241. doi:10.1016/j.ijdrr.2015.06.001

Guillard-Gonçalves C, Zêzere JL, Pereira S, Garcia RAC (2015) Assessment of physical vulnerability of buildings and analysis of landslide risk at the municipal scale-application to the Loures municipality. Portugal Nat Hazards Earth Syst Sci Discuss 3:5547-5597. doi:10.5194/nhessd-3-5547-2015

Haimes YY (2009) Risk modeling, assessment, and management, 3rd edn. Wiley, London 
Harrell F, Jr (2001) General aspects of fitting regression models. In: Regression modeling strategies. Springer Series in Statistics. Springer, New York, pp 11-40. doi:10.1007/978-1-4757-3462-1_2

Hufschmidt G, Glade T, Hufschmidt G, Glade T (2010) Vulnerability analysis in geomorphic risk assessment Geomorphological Hazards and Disaster Prevention. Cambridge University Press, Cambridge

Hussin $\mathrm{H}$ et al (2014a) Assessing the effect of mitigation measures on landslide hazard using 2D numerical runout modelling. In: Sassa K, Canuti P, Yin Y (eds) Landslide science for a safer geoenvironment. Springer, Berlin, pp 679-684. doi:10.1007/978-3-319-05050-8_105

Hussin HY, Chen L, Ciurean RL, van Westen CJ, Reichenbach P (2014b) Analysing changes in landslide risk using multi temporal landslide susceptibility and run-out modeling on a regional scale. Paper presented at the International Conference on Analysis and Management of Changing Risks for Natural Hazards, Padova, Italy, 18-19 November 2014

Hussin HY, van Westen CJ, Reichenbach P, Sterlacchini S, Frigerio S, Marcato G, Calligaris C (2015) Quantifying landslide intensity for hazard assessment on a regional scale in the Eastern Italian Alps (manuscript in preparation)

Kaynia AM, Papathoma-Köhle M, Neuhäuser B, Ratzinger K, Wenzel H, Medina-Cetina Z (2008) Probabilistic assessment of vulnerability to landslide: application to the village of Lichtenstein, BadenWürttemberg, Germany. Eng Geol 101:33-48. doi:10.1016/j.enggeo.2008.03.008

Keiler M (2011) Geomorphology and Complexity—inseparably connected? Zeitschrift für Geomorphologie 55:233-257

Li Z, Nadim F, Huang H, Uzielli M, Lacasse S (2010) Quantitative vulnerability estimation for scenariobased landslide hazards. Landslides 7:125-134. doi:10.1007/s10346-009-0190-3

Malek Ž, Scolobig A, Schröter D (2014) Understanding land cover changes in the Italian Alps and Romanian Carpathians: combining remote sensing and stakeholder interviews. Land 3:52-73

Mavrouli O, Corominas J (2010) Vulnerability of simple reinforced concrete buildings to damage by rockfalls. Landslides 7:169-180. doi:10.1007/s10346-010-0200-5

Mavrouli $\mathrm{O}$ et al (2014) Vulnerability assessment for reinforced concrete buildings exposed to landslides. Bull Eng Geol Environ 73:265-289. doi:10.1007/s10064-014-0573-0

Mazzorana B, Levaggi L, Formaggioni O, Volcan C (2012) Physical vulnerability assessment based on fluid and classical mechanics to support cost-benefit analysis of flood risk mitigation strategies. Water 4:196-218

Negulescu C, Foerster E (2010) Parametric studies and quantitative assessment of the vulnerability of a RC frame building exposed to differential settlements. Nat Hazards Earth Syst Sci 10:1781-1792. doi:10. 5194/nhess-10-1781-2010

Papathoma-Kohle M, Totschnig R, Keiler M, Glade T (2012) A new vulnerability function for debris flow. The importance of physical vulnerability assessment in alpine areas. In: 12th Congress Interpraevent, April 23-26 2012, Grenoble, France

Papathoma-Köhle M, Kappes M, Keiler M, Glade T (2011) Physical vulnerability assessment for alpine hazards: state of the art and future needs. Nat Hazards 58:645-680. doi:10.1007/s11069-010-9632-4

Papathoma-Köhle M, Keiler M, Totschnig R, Glade T (2012) Improvement of vulnerability curves using data from extreme events: debris flow event in South Tyrol. Nat Hazards 64:2083-2105. doi:10.1007/ s11069-012-0105-9

Papathoma-Köhle M, Zischg A, Fuchs S, Glade T, Keiler M (2015) Loss estimation for landslides in mountain areas-an integrated toolbox for vulnerability assessment and damage documentation. Environ Model Softw 63:156-169. doi:10.1016/j.envsoft.2014.10.003

Pate-Cornell ME (1996) Uncertainties in risk analysis: six levels of treatment. Reliab Eng Syst Saf 54:95-111

Quan Luna B, Blahut J, van Westen CJ, Sterlacchini S, van Asch TWJ, Akbas SO (2011) The application of numerical debris flow modelling for the generation of physical vulnerability curves. Nat Hazards Earth Syst Sci 11:2047-2060. doi:10.5194/nhess-11-2047-2011

Quan Luna B, Blahut J, Camera C, van Westen C, Apuani T, Jetten V, Sterlacchini S (2014) Physically based dynamic run-out modelling for quantitative debris flow risk assessment: a case study in Tresenda, northern Italy. Environ Earth Sci 72:645-661. doi:10.1007/s12665-013-2986-7

Remondo J, Bonachea J, Cendrero A (2008) Quantitative landslide risk assessment and mapping on the basis of recent occurrences. Geomorphology 94:496-507. doi:10.1016/j.geomorph.2006.10.041

Rougier JC, Beven KJ (2013) Model and data limitations: the sources and implications of epistemic uncertainty. In: Rougier JC, Sparks S, Hill L (eds) Risk and uncertainty assessment for natural hazards. Cambridge University Press, Cambridge, pp 19-40

Schwendtner B, Papathoma-Köhle M, Glade T (2013) Risk evolution: how can changes in the built environment influence the potential loss of natural hazards? Nat Hazards Earth Syst Sci 13:2195-2207. doi:10.5194/nhess-13-2195-2013 
Silva M, Pereira S (2014) Assessment of physical vulnerability and potential losses of buildings due to shallow slides. Nat Hazards. doi:10.1007/s11069-014-1052-4

Sterlacchini S, Akbas S, Blahut J, Mavrouli O-C, Garcia C, Luna B, Corominas J (2014) Methods for the characterization of the vulnerability of elements at risk. In: Van Asch T, Corominas J, Greiving S, Malet J-P, Sterlacchini S (eds) Mountain risks: from prediction to management and governance, vol 34: advances in natural and technological hazards research. Springer, Dordrecht, pp 233-273. doi:10. 1007/978-94-007-6769-0_8

Totschnig R, Fuchs S (2013) Mountain torrents: quantifying vulnerability and assessing uncertainties. Eng Geol 155:31-44. doi:10.1016/j.enggeo.2012.12.019

Totschnig R, Sedlacek W, Fuchs S (2011) A quantitative vulnerability function for fluvial sediment transport. Nat Hazards 58:681-703. doi:10.1007/s11069-010-9623-5

UNDRO (1984) Disaster prevention and mitigation-a compendium of current knowledge Preparedness Aspects 11

Uzielli M, Catani F, Tofani V, Casagli N (2015) Risk analysis for the Ancona landslide-II: estimation of risk to buildings. Landslides 12(1):83-100. doi:10.1007/s10346-014-0477-X

Uzielli M, Nadim F, Lacasse S, Kaynia AM (2008) A conceptual framework for quantitative estimation of physical vulnerability to landslides. Eng Geol 102:251-256. doi:10.1016/j.enggeo.2008.03.011

van Westen CJ, Asch TWJ, Soeters R (2006) Landslide hazard and risk zonation-why is it still so difficult? Bull Eng Geol Environ 65:167-184. doi:10.1007/s10064-005-0023-0

Walker WE, Harremoes P, Rotmans J, van der Sluijs JP, van Asselt MBA, Janssen P, van Krauss MPK (2003) Defining uncertainty: a conceptual basis for uncertainty management in model-based decision support. Integr Assess 4(1):5-17

Winter MG, Smith JT, Fotopoulou S, Pitilakis K, Mavrouli O, Corominas J, Argyroudis S (2014) An expert judgement approach to determining the physical vulnerability of roads to debris flow. Bull Eng Geol Environ. doi:10.1007/s10064-014-0570-3 